\title{
Self-help groups, savings and social capital: Evidence from a field experiment in Cambodia
}

\author{
Radu Ban ${ }^{\mathrm{a}, *}$, Michael J. Gilligan ${ }^{\mathrm{b}, *}$, Matthias Rieger ${ }^{\mathrm{c}, *}$ \\ a Bill and Melinda Gates Foundation, 500 5th Ave N, Seattle, WA 98109, United States \\ ${ }^{\mathrm{b}}$ Department of Politics, New York University, 19 West 4th Street 2nd Floor, New York, NY 10012, United States \\ ' Institute of Social Studies of Erasmus University Rotterdam, Kortenaerkade 12, 2518AX Den Haag, Netherlands
}

\section{A R T I C L E I N F O}

\section{Article history:}

Received 17 January 2020

Revised 10 August 2020

Accepted 26 September 2020

Available online 22 October 2020

\section{JEL classification codes:}

01

I3

Q1

D71

C93

\section{Keywords:}

Social capital

Poverty

Savings

Self-help groups

Field experiments

Cambodia

\begin{abstract}
A B S T R A C T
Do self-help groups (SHGs), village-based associations designed to encourage savings, household production and social cohesion among the poor, meet their goals? We examine economic outcomes and the pro-social behavior of 540 households in a randomized control trial (RCT) of a SHG program (randomized at the commune level) in rural Siem Reap, Cambodia using survey data and a rich set of economic and social capital indicators. We measured social capital-defined as social norms and the social networks that support them-with household and network surveys and lab activities that gauge altruism, trust, trustworthiness and the willingness to contribute to public goods. We find that the program successfully increased participation in SHGs and strengthened SHG-related networks. As intended the program significantly increased the number of households with non-zero savings as well as savings levels and it led to a noticeable shift in household production towards livestock. We cannot document increases in household incomes, assets or expenditure. There were also no sizeable wider effects on social capital and networks other than those related to SHGs directly, although we cannot statistically rule out small positive effects in the case of some social capital indicators. In addition to these empirical findings the study provides an example of innovative program evaluation techniques that employed a field experiment, lab-in-the-field behavioral measures, network measures as well as traditional survey measures.
\end{abstract}

(C) 2021 The Authors. Published by Elsevier B.V. This is an open access article under the CC BY license (http://creativecommons.org/licenses/by/4.0/)

\section{Introduction}

We evaluate the impact of an eighteen-month-long program to promote economic and social empowerment among the poor in rural Siem Reap, Cambodia. The program, called LEAP (Livelihood Enhancement and Associations among the Poor), pursued these goals by establishing self-help groups (SHGs): "village-based organizations that focus on building the savings and credit as well as social empowerment of their (mostly female) members.” (see Desai and Joshi, 2013, p.3; citing Chen et al. 2007). The program randomized at the commune level created 100 such groups serving 1291 members in rural areas of Siem Reap province. Our randomized evaluation examines economic outcomes and the pro-social behavior of 540 households.

We designed our research with three questions in mind: did the program increase savings; did it enhance livelihoods and did it increase civic engagement and social capital among the poor? We found robust and positive evidence for the

\footnotetext{
* Corresponding authors.

E-mail addresses: radu.ban@gatesfoundation.org (R. Ban), mg5@nyu.edu (M.J. Gilligan), rieger@iss.nl (M. Rieger).
} 
first question: Savings (both their likelihood and levels) and related participation in SHGs increased substantially. The robust and positive savings and SHG creation effects from this short eighteen-month program with a sample size of only 540 are noteworthy, which indicates that the program was quite successful at its primary goal. ${ }^{1}$

We could not find consistent evidence of success on the program's other two goals though. Households in treated communities moved into meat production and out of other income-generating activities including plant cultivation which is more difficult in the program area's relatively dry climate compared to the rest of Cambodia. The extent of any overall improvements to livelihoods remains uncertain. Overall production incomes and assets did not increase significantly over the year and a half of the program possibly due to brevity of the program.

The same is largely true with broader social change. While the program fostered greater networking via SHGs, the program's networking effects did not generally extend to other sorts of networks. Average effects were in the small to medium range for economic and social networks but they were statistically insignificant, pointing to low-powered test. Subjects in treated communities exhibited only slightly more pro-social behavior in laboratory activities or community service than did subjects in control communities, and these small positive effects are insignificant statistically. We did find promising evidence of greater group participation in treated communities. This average result was driven entirely by an increase in membership in rice seed banks. These seed groups were not created by LEAP but they are prevalent in our study area and seem to complement SHGs even in the absence of LEAP, suggesting that there were some downstream social changes due to the program.

As discussed in the literature review, one of our innovations over existing RCTs of savings and self-help groups is a more extensive set of social capital measures in addition to looking at a host of economic outcomes. Here we apply the widelycited definition of social capital by Putnam (2000, p. 19): “... social networks and the norms of reciprocity and trustworthiness that arise from them." We strived to capture these key components of social capital directly. We measured the networks across several domains after extensive focus group research in the region. To measure norms, we devised lab-in-the-field techniques to record subjects' norms, observing their behavior in structured and incentivized choice activities. We also implemented a standard household survey covering a range of self-reported economic and social activities. In this way, we followed Chuang and Schechter's (2015, p. 151) advice: "in a developing-country context, researchers should explore designing simpler experiments and including survey questions in addition to experiments when measuring preferences."

Our study is set in an interesting social context. Previous qualitative and lab-in-the-field research has indicated that social capital in Cambodia is weak. Kerbo (2011) and Colletta and Cullen (2000) describe levels of trust that are particularly low even 30 years after the country's genocidal war. In a sentiment expressed by many of Kerbo's interviewees, a Cambodian NGO worker described the Cambodia people thusly: "They have lost much of their trust in fellow citizens that existed before the civil war and Khmer Rouge days." (p.173-4). Kerbo describes Cambodia as a country that is "missing civil society" (p.183). Weingart and Kirk (2012) found levels of trust and trustworthiness to be relatively low levels compared to other countries. These findings point to an important impediment to social and economic development in the study area and the need for improvement sought by LEAP.

The social-capital-creating mechanism we have in mind is the one modeled by Avdeenko and Gilligan (2015). In that model, following Putnam's definition quoted above, people apply two different sets of norms, one for members of their social network and one for members outside their social network. The former set of norms is more trusting and altruistic and in general pro-social than the latter set of norms because it is supported and enforced by a set of rules and relationships within the social network. A program like LEAP, then, would enhance social capital by expanding social networks so that in-network more prosocial norms are applied to a larger group of people. While we find strong treatment effects on participation in SHGs and SHG-related networks, these do not correlate with pro-social behavior, and effects on wider networks may have been too limited to induce more substantial changes in pro-social behavior as suggested by this theory.

Another possible mechanism is inequity aversion (Fehr and Schmidt, 1999). ${ }^{2}$ If a development intervention successfully improves an individual's economic position, altruism towards needier members in the community could increase. This mechanism running from economic to social outcomes would be consistent with social preferences featuring aversion towards inequity experienced by others as proposed by Fehr and Schmidt (1999). Indeed, we find that total annual household production correlates positively with altruism towards needy households in the communities as measured by a dictator game. ${ }^{3}$ Likewise, savings levels correlate positively with willingness to contribute to the community in a public good game. However, while the program appeared to cause large increases in savings, household production was not significantly increased by LEAP and may have been too small to cause larger increases in pro-social behavior.

This paper is organized as follows: Section 2 systematically reviews the previous literature and underlines the valueadded of this study. Section 3 describes the program. Section 4 details the empirical strategy. Section 5 presents the results. Section 6 concludes.

\footnotetext{
1 As we describe in section 3 below, LEAP planned to work with each self-help group for a total of three years. However, the intervention was not fully implemented due to some general and sudden funding stops following disagreements over land evictions (unrelated to LEAP) between the World Bank and the Cambodian government. The situation only improved in 2016: World Bank Will Resume Funding to Cambodia, The Cambodia Daily, May 21, 2016. Available at: https://www.cambodiadaily.com/editors-choice/world-bank-will-resume-funding-to-cambodia-112866/ [Accessed July 4 2019].

2 We thank an anonymous referee for proposing to examine this mechanism ex-post.

${ }^{3}$ We ran these correlational regressions in the control group to abstract from treatment-related changes in social and economic outcomes.
} 


\section{Previous research and contribution of present study}

Microfinance programs can be divided into three broad categories: microcredit, savings, and self-help programs. In microcredit programs, outside lenders (commercial banks, government agencies or non-governmental organizations) make small loans to groups. Microcredit programs bring new outside capital into communities and are sometimes called microloan programs for this reason, but they place no necessary emphasis on savings or asset accumulation by their members. Savings groups, as the name implies, do place an emphasis on savings and asset accumulation. Members of savings groups make regular contributions to a pool and apply for loans from that pool. The group awards loans according to a fixed decision rule. No outside capital is necessarily injected into these programs, although in many cases a small amount of seed money or matching funds may be provided by the program organizer. Savings groups programs go by a variety of names including village savings and loan associations (VSLAs), accumulating savings and credit associations (ASCAs) and savings and internal lending committees (SILCs).

While both microcredit groups and savings groups attempt to foster economic empowerment, neither, by our reading, necessarily attempt to create social capital, political and social empowerment or civic engagement. If anything, rather than using these groups to create social capital these programs appear to be designed to piggyback on existing social capital, using social pressure to induce higher rates of loan repayment and savings respectively (Attanasio et al., 2015; Kast et al., 2012; Ghatak and Guinnane, 1999). SHGs, the object of our study, are different in this regard: they explicitly attempt to foster social capital, social empowerment and political participation. Put another way SHG programs are savings groups plus social capital training and encouragement (Desai and Joshi, 2013; Carter, 2013).

To limit our review to an acceptable length we concentrate on the three outcomes that are the focus of this study: savings, livelihood enhancements and the formation of social capital. Furthermore, we include only studies that have an explicit strategy to causally identify program impacts. For readers interested in a general review of microfinance programs we recommend the helpful reviews by Brody et al (2017),Entz et al. (2016), Graafland and Rijnevald (2016), Gash and Odell (2013); van Rooyen et al. (2012); Duvendack et al. (2011) and Fernandez (2006).

The studies that meet our criteria are summarized in Table 1. Each study occupies a row of the table. This first column lists the citation of the study. The study's identification strategy is specified in the second column: PSM stands for propensity score matching, DD stands for difference in difference and RCT stands for randomized control trial. "Pipeline" is a method applied to observational data in which new members are compared to older members based on the claim that those two groups are statistically interchangeable. The second column lists the locus of the treatment, whether it was administered at the village level (as in our case), the group level or the individual member. The next five columns indicate the results of the study (if any) on the outcomes in which we are interested: savings, livelihoods, and three social capital measures.

There is a strong consensus in the literature that SHGs improve savings. Five of the six SHG studies in Table 1 that offer findings on savings (including this one) registered significant increases in savings as a result of the programs they evaluated. ${ }^{4}$ Deininger and Liu (2013a, p. 156) do not report on savings accumulation but in their study program beneficiaries reported a significantly greater "ability to save individually," meaning they had their husband's permission to save individually. Khanna et al. (2015) do not report results on cash savings but show that the program they studied increased non-financial assets, mainly household durables and livestock. Savings groups also generally exhibit a positive impact on savings. All of the SG studies in Table 1 report significant increases in savings. ${ }^{5}$ Finally, microcredit programs show little impact on savings, a not-unexpected result given that the purpose of these programs is to make loans, not encourage savings. Indeed, only four of the microcredit studies in Table 1 even report on savings and only one of these showed an increase in savings.

There is a similar consensus in the literature on the effects of SHG and SG programs on livelihoods. Each study defined livelihood improvement somewhat differently. Four of the six SHG studies that report findings on livelihoods found that the programs they evaluated improved them. Khanna et al. (2015) found that the program they studied shifted livelihood portfolios toward higher skilled and more secure jobs. Desai and Joshi (2013) find that the program they study caused a significant increase in employment outside of agriculture, which was particularly beneficial in the drought-stricken period of their study. Swain and Varghese (2009) focus on asset creation but they did find significant increase in group members' total incomes which we take as a sign of livelihood improvement. Datta (2014) found no improvement in livelihoods, measured as shifts toward a particular livelihood and away from others. He also found no increase in the number of income earners in treated households. He does report a robust increase in animal husbandry of one-half a percent, but still concludes overall that the program did not improve livelihoods. Our results are surprisingly similar to Datta's. We found significant shifts toward animal husbandry but only a small (of 0.1 standard deviations) and statistically insignificant average effect on overall production outcomes.

\footnotetext{
4 We do not include Greaney et al (2016) in Table 1 because they did not test the effects of savings groups but of the method of creating those groups. They examined whether a program that paid private agents to set up savings groups was as effective as a traditional program where outside NGOs help set up these groups. They found that the private-agent scheme produced similar amounts of saving as the NGO model at lower cost. However private agents tended to produce greater savings for business rather than households.

5 Deininger and Liu (2013b), which is not listed in the Table 1 because it does not report on any of the outcomes in Table 1 also showed a significant increase in assets, mainly livestock.
} 
Table 1

Summary of the Literature.

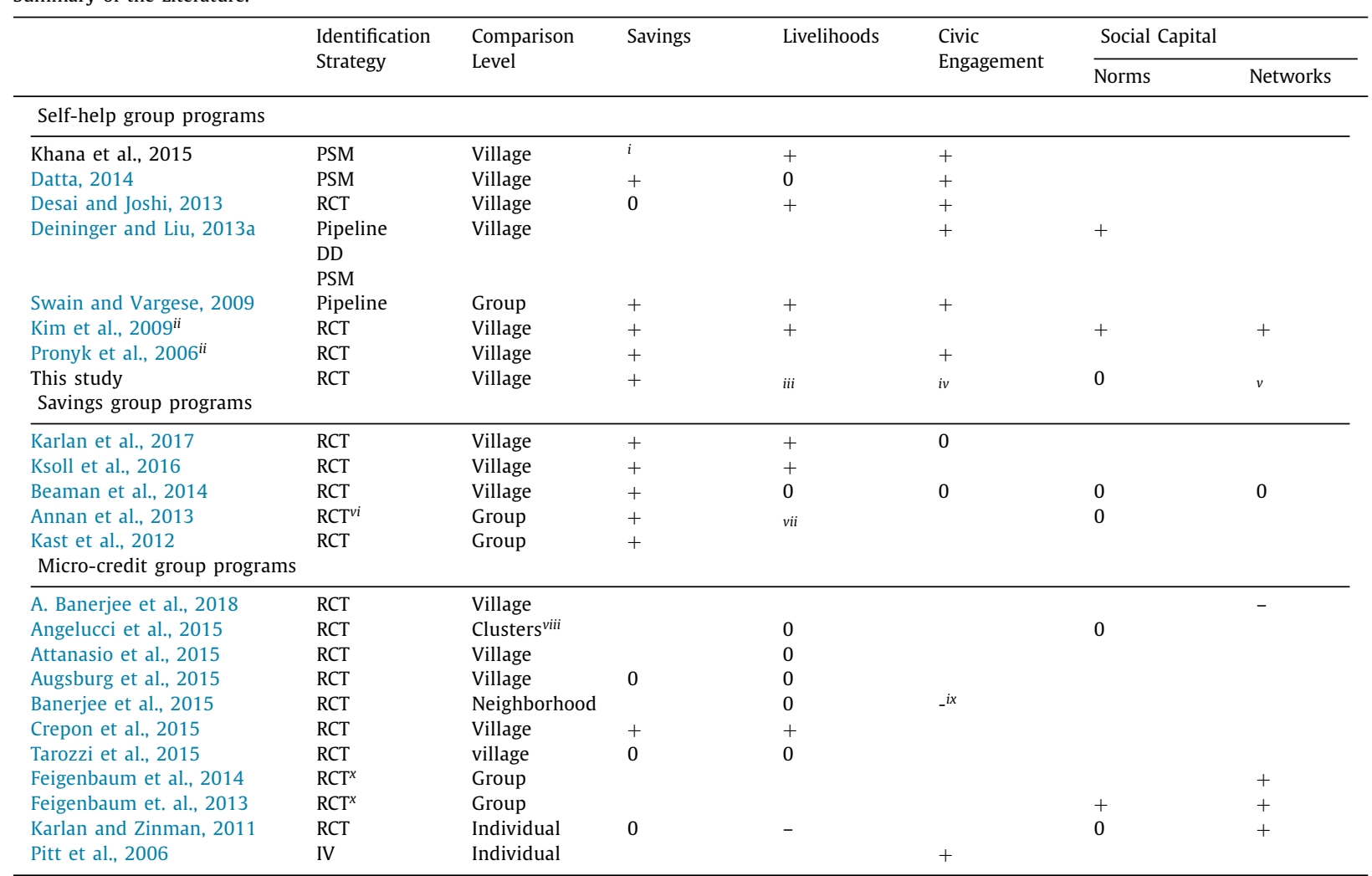

${ }^{i}$ These studies report statistically significant accumulation of non-financial assets but do not report impacts on savings.

${ }^{i i}$ Kim et al. and Pronyk et al. are distinct but very similar studies of the same program in Limpopo, South Africa. It was a micro-credit program that included self-help training.

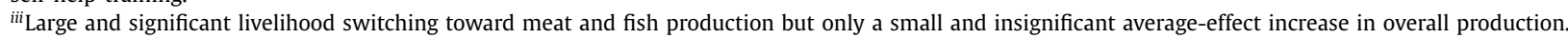

${ }^{i v}$ Borderline significant average-effect increase in group participation driven entirely by large and significant increase in rice seed group membership.

${ }^{v}$ Large and significant increase in SHG networks; no significant increase in other social or economic networks.

${ }^{v i}$ A randomly-chosen half of the groups began the program immediately and the other half a year later.

${ }^{\text {vii }}$ They did not examine livelihoods but determined that the program did cause a significant reduction of households below the poverty line.

viii Clusters were neighborhoods in urban settings and villages or groups of villages in rural settings.

${ }^{i x}$ The program caused a reduction in household spending on community festivals, indicating some reduction in civic engagement. The study did not address other civic engagement.

${ }^{x}$ Some randomly selected groups met weekly and the remainder met monthly.

${ }^{x i}$ Their sole measure of livelihoods was size of subjects' business enterprises, which they found shrunk.

xii They did not compute average effects. Treated individuals exhibited significantly more self-reported trust in their neighbors but were no more trusting according to three other measures. We suspect average effects were zero.

xiii They only asked about friends and family networks. Respondents in treated communities were more confident in the strength of those network ties: they reported significantly more confidence in relying on friends and family for large amounts of financial assistance in an emergency.

Three of the four SG studies that covered livelihoods found positive impacts. The program Ksoll et al. (2016) studied caused an increase in business incomes. Karlan et al. (2017) found that the program that they studied over three countries improved an index composed of three business outcomes (number of businesses operated, months of operation in the preceding year and number of employees). Beaman et al. (2014) did see increases in business income but no significant increases in small business profits or ownership. The program they studied also caused no increase in agricultural output. Annan et al. (2013) did not report on livelihood outcomes but did report a significant reduction in households in poverty as a result of the SG program they study. Most studies of microcredit programs found no impact on livelihoods. The one exception was Crepon et al. (2015) who found strong evidence of improved livelihoods: greater investment in and profit from self-employment activities and less reliance of casual labor. Karlan and Zinman (2011) found that the size of treated subjects' business enterprises actually shrunk compared to control subjects, however they did not assess other livelihood measures like income, skill accretion or job security.

As mentioned above SHGs explicitly strive to improve their members' social empowerment through civic engagement while SGs and microcredit groups tend to focus more narrowly on economic empowerment. This extra feature of SHGs is reflected in the literature: all but one of the studies of SHG programs evaluated the effect of their program on civic engagement. Only three SG and two microcredit studies did so and of those five only one found a positive impact. 
There is strong agreement in the literature that SHGs cause greater civic engagement, generally in the form of greater attendance at community meetings. In addition, Desai and Joshi (2013) determined that members of treated communities possessed greater knowledge about their local government. In keeping with their focus on economic rather than social outcomes studies of savings groups address civic participation less commonly. Karlan et al. (2017) and Beaman et al. (2014) did ask respondents about attendance at community meetings, raising an issue with community leaders and other forms of civic participation but found no effect of the programs they studied. Concern with civic engagement is even less common in studies of microcredit groups. Pitt et al. (2006) were particularly interested in women's empowerment so they did ask whether members of the microcredit groups they studied were more likely to attend community meetings and found that they did. Banerjee et al. (2015) were not interested in civic engagement per se but they were interested in consumption so they did examine household expenses on community festivals. They found that members of the microcredit group they studied spent significantly less on community festivals, suggesting a possible pathway between microcredit groups and a reduction in civic participation.

Social capital, measured by pro-social community norms and social networks to support them, have been rarely studied in this literature even in studies of SHGs. Besides this study only Deininger and Liu (2013a) and Kim et al. (2009) address the effects of the programs they study on social norms and networks. Deininger and Liu (2013a) found that residents of treated communities self-reported significantly greater trust in community members and public officials than villagers in control communities. Respondents in Kim et al. (2009) recount having larger social networks and subjectively assess greater community support and solidarity. Unlike our study both of these studies did not use behavioral measures of norms but relied on self-reports, which raises concerns about social desirability bias in self-reports in the treated communities. Beaman et al. (2014) is the only SG study that addressed networks and norms. They asked if the respondent could borrow from or would be willing to lend to another woman in the community or would go to the market with a woman in the sample. It is unclear whether responses to these questions are measures of networks or norms. Regardless, the results effects of the program were very small and statistically insignificant.

Generally, studies of microcredit programs do not address social capital. The two papers by Feigenbaum and his coauthors are notable exceptions. They show that members' social networks are enhanced by participation in the Grameen-style program they study. Both papers found that women in groups that met more frequently had more social contact than women who met less frequently. Feigenbaum et al. (2014) also used a public goods game to measure pro-social norms and found that women who met more frequently exhibited greater pro-social norms. This latter article is the only other study (besides ours) that used behavioral measures in the study of microfinance. While they did not explicitly try to measure social capital Karlan and Zinman (2011) did ask about friends and family networks in their study of a microcredit program in the Philippines. Respondents in treated communities reported significantly greater confidence in relying on friends and family for large amounts of financial assistance in an emergency, suggesting stronger friends and family networks in treated communities. Karlan and Zinman (2011) also asked about trust but found no significant impact of the program they studied. Finally, Angelucci et al. (2015) found an increase in trust in people but no effect on trust in institutions. Bannerjee et al. (2018) focused on networks and found that participation in microcredit groups reduced the number of network links in their large sample of Indian villages. One possible reason for the disparity between the results of Bannerjee et al. and those of Feigenbaum at al and Karlan and Zinman is that Bannerjee et al. measured the quantity of links while the other three papers focused on those link's quality.

Two studies, not listed in Table 1 because they do not directly address our outcomes of interest, hint at the development of social capital while not providing direct evidence of it. Using a survey of local public officials and SHG members in India, Casini and Vandewalle (2017) found that SHG members' community action on issues important to them spurred greater action on those issues by local public officials. Fafchamps and La Ferrara (2012) provide evidence that SHGs serve as mutual assistance groups, helping to insure members against negative household shocks.

To summarize, both SGs and SHGs improve savings and (although the evidence is a bit less strong) livelihoods. Microcredit groups have no appreciable effects on these outcomes. SHGs promote civic engagement while SGs do not, which is neither surprising nor a criticism of SGs because their raison d'être is economic not social empowerment. While the evidence that SHGs promote civic engagement is strong the evidence that SHGs promote social capital (defined as social networks and the pro-social norms they encourage) is sparser, not because it does not exist, but because scholars have not looked for it. Indeed, in the few cases where research has looked for impacts on networks and norms (including this paper) it has found them. Finally, while there is some evidence that microcredit groups promote some social capital that evidence is scant.

The take-ways from Table 1 are that SHGs and SGs are much more successful at bringing about positive social change than microcredit programs are. SGs and SHGs improve savings and livelihoods while there is no tangible evidence that microcredit programs do. SHGs have the added benefit over SGs that they promote civic engagement and social capital. Although the evidence on SHG's impacts on social capital is very promising, it is not as extensive as the evidence on civic engagement. More study on the effects of SHGs on networks and norms would be worthwhile.

\section{Background and program description}

Siem Reap hosts Cambodia's majestic Angkor Wat temple. Areas close to the temple have experienced a tourism boom with millions of tourists every year, and as a result the area around the temple including the town of Siem Reap has seen 


\author{
July 2010 - \\ LEAP pilot starts / \\ Province-wide \\ LEAP project and \\ related study \\ preparations
}

July/November 2012 -

Pilot SHGs operate

without external support
April 2013 -

Impact evaluation

of pilot intervention

via lab-in-the field

experiments and

household survey

(focus of this

paper)

\begin{abstract}
May 2010 -
Study planning

and design for a

province-wide

LEAP roll-out
\end{abstract}
July 2012 -
Interruption of
LEAP's overall
and pilot project

\author{
November 2012 - \\ SHGs receive \\ $\underline{\text { additional financial }}$ \\ support
}

Fig. 1. Timeline.

explosive economic growth. However, this tourism boom has not reached parts of the province some miles away from Angkor Wat and the city. Large parts of the local population do not have the education levels or English language skills needed to benefit from this boom directly. In a 2008 study, 14\% of Siem Reap province residents were considered very poor (ID Poor 1) and another 15\% were considered poor (ID Poor 2) despite the substantial tourism flows to Angkor Wat temple. ${ }^{6}$

To combat persistent poverty in the rural areas of Siem Reap, the Cambodian government and the World Bank launched LEAP, initially as a pilot project. LEAP had three official, pro-poor objectives: 1) building and strengthening SHGs among the poor to facilitate collective action with and serve as intermediaries to state and lending institutions, 2) providing the poor with better access to finance and 3) forging better links between poor producers and important markets and value chains. The program hoped that through these activities the villages would accumulate social capital which would in turn strengthen villagers' trust, trustworthiness and capacity for collective action in pursuing these goals.

LEAP inputs included coordination activities, training programs, monitoring as well as cash in the form of seed grants (see LEAP, 2012). Under the first component, SHGs were formed and trained (e.g. management, bookkeeping, and meeting facilitation). Individual SHG members were instructed on how to increase savings and make and obtain loans. They were trained in gender mainstreaming and agricultural techniques. They also received information on civic participation, the identity and responsibilities of their government officials and how to approach them with their concerns. The SHGs were closely monitored to ensure regular and well attended meetings, steady saving and lending, adherence to internal group rules and proper bookkeeping. All SHGs were officially registered with the commune council. Each SHG also underwent an extensive performance rating and received overall performance scores. Groups met weekly for training and contributed to the savings pool monthly. As part of the second component, all SHGs opened formal bank accounts and received seed grants to kickstart activities. The third component involved the establishment of producer groups, the provision of livelihoods training (e.g. home-gardening, chicken-raising), as well as the promotion of market linkage of producer groups.

The timing of the LEAP pilot (and our involvement) was as follows (see timeline in Fig. 1). Members of the Cambodian LEAP team met with the authors in May 2010 at a conference in Dubai as part of the World Bank's Development Impact Evaluation (DIME) initiative where we began the first stage of designing the randomized evaluation for a project covering the entire province. The funding source (the World Bank) facilitated this exchange. For transparency note that the first author was working at the funding source at the time. As part of the randomization for the province-wide impact evaluation, we randomly selected the pilot communes to receive the program in June and LEAP launched the smaller pilot program in July of 2010, too soon after we were brought on to gather baseline data. The pilot phase ran until July 2012 and was supposed to be followed with and inform the full implementation of the program (accompanied by our full impact evaluation building on household and behavioral baseline data collection), however for reasons beyond LEAP's control and responsibility, World Bank funding ceased and the pilot and subsequent full programs entered a period of budgetary uncertainty (LEAP, 2012; see footnote 3). From July through November 2012 pilot SHGs continued to meet without outside support. LEAP received a small grant of almost 10,000 USD in November 2012 to support existing SHGs until January 2013. We began field work for this pilot evaluation in April 2013. The larger province-wide impact evaluation of course never materialized.

The LEAP pilot led to the following officially reported outputs (see LEAP, 2012): To ameliorate the social institutions of the poor, LEAP created 100 self-help groups with 1291 household members, 90 percent of whom were female. To improve savings and access to credit all 100 SHGs opened bank accounts at major commercial banks. Program staff reported that these 100 SHGs had accumulated total savings of about 78,000 USD at the time of our study in late April and early May of

\footnotetext{
6 The Ministry of Planning in Cambodia runs a program for the identification of the poor, IDPoor for short. The categorization of households by poverty status aids with program targeting. Using surveys, authorities put households in one of two poor groups (IDPoor 1 and IDPoor 2 ) or neither. IDPoor 1 are the very poor, struggling to have enough food. IDPoor 2 are less poor, living between the food poverty line and the poverty line. If the household is in neither group we consider them non-poor. About 15 percent of the Cambodian population fall into each of the categories IDPoor 1 and IDPoor 2 (see Ministry of Planning, 2013a,b).
} 
2013. ${ }^{7}$ As of May 2012, over 5800 loans had been made from SHG funds, $85 \%$ for investments and $15 \%$ for consumption and the program had made over 33,000 USD in seed grants to the SHGs. On average each SHG received USD 336 corresponding to 26 USD per participating household. To boost the poor's access to markets and value chains these 100 SHGs reportedly created 52 producers' groups, 38 in chicken raising (73\% of the total), seven in pig raising, four in basket weaving, two in vegetable raising and one in rice selling. Our findings reported in Section 5 raise questions about how active these groups actually were, at least at the time of follow up.

\section{Empirical strategy and data}

Our evaluation was designed to test three propositions: First, we were tasked with determining whether the program increased savings and access to credit. Second, we were asked to evaluate whether greater access to credit and LEAP's programs to better link poor villagers to markets produced livelihood enhancements. Finally, we were asked to ascertain whether the program increased civic engagement and social capital among the poor. The program's interest in social capital was motivated by an interest in encouraging the poor to take collective social action to address issues important to them. Any evidence that we could find that LEAP produced social capital, especially among the poor, would be taken as an extremely important impact of the program by the program's designers.

\subsection{Measurement}

We collected data to measure the savings, livelihoods and broader social impacts of the program in three ways. First, we conducted an extensive randomly sampled household survey in treated and control communes to measure the respondents' savings behavior, improvements in livelihoods, consumption behavior and incomes. This survey provided our measures of assets, savings, expenditures and livelihood activities. We also asked questions about civic participation and group membership that we use as social capital measures in combination with the measures described below to complete the picture of the social context of the villages. After completion of the survey, the household head (or their partner) was invited to participate in an experimental session and the collection of network data.

Networks form a key part of social capital, so we recorded socio-economic links between our laboratory subjects, essentially taking a snapshot or random sample of the overall community network. ${ }^{8}$ More specifically, we collected data on the matrices of relationships across several socio-economic domains. We picked the most relevant domains for the impact evaluation following extensive focus group discussions (such as self-help group links, labor exchange, regular buying and selling). Our enumerator recorded the network links during a group discussion, which allowed crosschecking of links between participants. Sometimes individual participants would forget to mention a link, and others in the group would help to fill such gaps. Conversely, in some rare cases there was disagreement about a specific link between two subjects, which after some further discussion and continued disagreement we would not record. We employ the total number of links within a given group as our main network measure. The maximum number of possible links is 14 (The number of laboratory session attendees minus one). One caveat that also applies to our group membership measure from the household survey: conscious of our subjects' time and recall limitations, we did not record the duration of the link or how intense it was, which would have allowed us to investigate impacts along the intensive or extensive margins.

We also conducted lab-in-the field activities to evaluate impacts of LEAP on social capital, since we were worried that purely self-reported measures may be systematically biased (Avdeenko and Gilligan, 2015; Mansuri and Rao, 2013): treated (unlike control) units were exposed to LEAP program staff, which may directly or indirectly prime community members to give socially desired answers to questions such as 'Do you contribute to public goods?' or 'How trustworthy are your neighbors?' We opted for activities in a controlled setting to tease out potential behavioral impacts of the program. It is important to note that our subjects were incentivized and made choices anonymously. Relatedly, subjects did know that they were playing with somebody else from the group (such as in the trust game), but we did not reveal exact identities in order to preserve anonymity.

We thought that the advantages of this experimental approach (coupled with the use of more traditional survey-based measures) outweighed potential disadvantages such as those described by Levitt and List (2007). They argue that people may be more cooperative in the lab than they are in real life because lab monitors are authority figures, subjects are being monitored (Hawthorne effects), people use different heuristics in real life than they do in the lab and stakes in the lab are typically lower than they are in real life. Levitt and List are clearly leveling their criticism at the use of behavioral activities as absolute measures of social preferences. These concerns are mitigated when behavioral activities are used, as they are here, to compare social preferences of subjects in treated and control communities in a RCT. For our purposes subjects'

\footnotetext{
7 This statement by the program is somewhat at odds with our own findings. Our estimates, reported in section 5 below, indicate that each member had accumulated additional savings of about 7.5 USD. Total program savings of 78,000 USD reported by the program implies an average savings of 60 USD for each of the 1291 members. Subtracting the seed-grant average of 26 USD per member still leaves 34 USD per member, considerably in excess of our finding. It is possible that the 78,000 figure is the peak amount accumulated by the program and the lower amount we found was due to the lack of support during the World Bank funding hiatus.

8 These network data were collected after the social capital experiments (discussed next), so there are no concerns related to priming effects running from networks to prosocial behavior.
} 
behavior in the lab does not need to match precisely their behavior in real life; it only needs to be positively correlated with it and any mismatches need to be uncorrelated with treatment. Since the treatment was randomized, worries about such correlation with the treatment are eased. To address the issue of small stakes we ensured that the payouts in our lab sessions were substantial. At the end of the experimental session, the average subject won about 16,500 riels (over four dollars), which corresponds roughly to one daily wage. Acting pro-socially in the lab actually costs the subjects something and for that reason we argue that it captures something of their true beliefs and preferences. Furthermore, one of Levitt and List's arguments about lab measurement is that context matters, people bring norms from the real world with them into the lab. But this was precisely our motivation: we used lab activities to gauge if norms in the treated villages are more pro-social than those in the control villages. Our lab-in-the field strategy therefor echoes Hoffman et al., 350): " $A$ one-shot game in a laboratory is part of a life-long sequence, not an isolated experience that calls for behavior that deviates sharply from one's reciprocity norm. Thus, we should expect subjects to rely upon reciprocity norms in experimental settings[...]." (see Avdeenko and Gilligan, 2015) Another common and more practical worry for lab-in-the field studies is a non-random selection of participants or lack of representativeness (Cardenas and Carpenter, 2008). As we show below, there was no systematic non-response to our random invitation to participate in the activities. Finally, we do not rely solely on behavioral measures but combine them with standard survey measures as recommended by Chuang and Schechter (2015).

We implemented five well-established lab-in-the-field activities. ${ }^{9}$ A similar strategy to measure social capital was used by Avdeenko and Gilligan (2015), Henrich et al. (2010), Schechter (2007), Karlan (2005), Henrich et al. (2004), and such activities have been widely used in the Global South (for an earlier review see Cardenas and Carpenter, 2008). Our three main activities were meant to capture subjects' pro-social behavior, closely following the procedures in Avdeenko and Gilligan (2015): altruism as expressed by the willingness to share with the needy, trust and trustworthiness and willingness to contribute to public goods. The remaining activities measured attitudes toward risk and intertemporal discounting.

The first activity captured altruism or generosity towards others in the community (benefiting others in need at a personal cost without receiving anything in return). In this simple activity, subjects received 3000 riels and we instructed them to choose how much of it (if anything) to transfer to a poor family in their community. We did not reveal the identity of the family for privacy reason and more importantly to measure undirected or pure altruism. Subjects made their choices seated at a table in a private choice area. We placed a sheet of paper with a dividing red line on the table. We then put six 500-riel notes in front of the subject and asked her to push the donation (if any) across the red line. We emphasized that the remainder of the money was paid out at the end of all activities.

Our second activity was a classic game to measure trust and trustworthiness (Berg et al., 1995). Unlike the previous activity, this investment game featured strategic interactions among our subjects. Each subject was randomly assigned to be an investor (or sender) or a trustee (or receiver) by drawing a number at the game station. We did not use these terms when explaining the activity in order to avoid priming effects, and simply referred to "Player 1" and "Player 2." We then anonymously matched each investor with a trustee. These pairs then interacted in two rounds: In round one, each player received a starting endowment of 3000 riels in notes of 500. Notes were again placed on a sheet of paper with a red line running though the center. The investor was asked in private (at the game table) how much she would like to send to the trustee (by pushing notes across the red line). We told the subjects that we would triple the amount they sent and give that amount to the trustee. The trustee would subsequently decide how much (if anything) of that total pool to return to the investor in the second round. If the investor sent say 1000 riels, the trustee would then have 6000 riels (their 3000 endowment plus the 3000 from the investor's decision) to decide how to allocate in the second round. We made this process clear by tripling the amount sent on the sheet of paper in front of subjects. In this first round, player 2, the trustee, did not make any decisions and we simply informed her about the starting endowments. After all players had visited the game table once, we proceeded to the next round, again player by player. This time, investors did not make any decision. Instead, trustees were shown how much they received (placing bills on the sheet of paper) and asked how much they would like to return (if anything) by pushing bills back across the red line.

Our third activity was played at the group level in the form of a dichotomous public good game akin to Barrett (2005). We gave two folded cards to each participant - one blank and one marked with an X inside the card. We then collected the cards in two rounds. For each X card handed in the first round, every subject in the group session received 500 riels. The other card was returned in the second round. If a subject handed in the blank card in the first round and kept the $\mathrm{X}$ card for the second round, she would receive 2000 riels in addition to 500 riels times the total number of X cards turned in by the group in the first round. In other words, subjects could contribute to the group or defect while still benefiting from contributions by other participants (viz. free riding).

We also conducted activities to measure risk and time preferences to complement our data on social preferences. Risk preferences may be correlated with trust and public good game behavior (Schechter, 2007) and therefore confound our outcomes of interests. Importantly, gambling is quite common in the study area, and we wanted to identify preferences for it, so in our fourth activity of the day, we elicited risk attitudes of subjects. Subjects picked from five lotteries featuring two outcomes each, decided with a coin flip. We kept the expected value across lotteries fixed at 2000 riels, only increasing variance. More specifically, the first lottery choice was risk-free. Subjects would receive 2000 riels independently of the coin flip. In the fifth lottery, subjects could win 4000 riels or zero, implying a variance in the expected payoff of 16,000 riels. The

\footnotetext{
9 Theses activities and the network survey were done by a different team than the household survey.
} 
pay-off table is available in the online appendix. We measured each subject's willingness to gamble for a higher payoff on a simple five-point scale. Other standard elicitation methods are more complicated, so we adopted this simpler one in order not to burden participants, especially since this was not an outcome variable. A risk averse person would strictly prefer the no-risk lottery and increasingly risk acceptant people would prefer increasing levels of risk. We cannot distinguish risk neutral people, but we simply wanted to control for gambling behavior, which as we discuss below was not a confounder in the end anyway.

The fifth and final activity captured time preferences or the level of patience. Subjects had to decide between receiving some money today (2000 riels) or a series of larger amounts after a week. In six choices, we gradually increased the future amount (2500, 3000...5000 riels), recording when subjects switched from an immediate payout to a delayed one (the table is shown in the online appendix). After a subject had completed the activity, she had to roll a dice to determine her payout. We use a six-point scale of patience, ranging between 1 (the subject always preferred an immediate payout) to six (the subject always preferred a delayed payout). ${ }^{10}$

Many of our subjects were illiterate. Following the advice of Cardenas and Carpenter (2008), we employed simple and visual instructions. Likewise, we were also forced to record behavior in our activities with the guidance of a facilitator at the game station (except in the public good game that was played in a group). Such close supervision is common (Karlan, 2005; Henrich et al., 2004), but can raise concerns relating to for instance social desirability bias or Hawthorn effects. However, all activities were implemented in the exact same way across communities. For instance, the roles and responsibilities of our survey team members were fixed, so any such effects should be balanced across treatment and control, and therefore should not bias point estimates.

Before any game play began, we explained to the subjects that they would receive their total payouts at the end of the experimental session. ${ }^{11}$ We did not give them a running total of their winnings over the course of the session. We explained all activities orally both to the group and to individuals at the game station following a detailed experimental script in Khmer. We provide the English script in the online appendix.

\subsection{Randomization and survey sample}

This section describes the randomization, sampling strategy, and empirical model. The LEAP team asked us to implement a rigorous randomized control trial in Siem Reap province in order to inform an eventual roll-out of the project in other provinces of Cambodia. To mitigate inter-village spillovers, we randomized at the commune level-the lowest administrative level above the village. The pilot was budgeted to run in all villages of six communes out of a total of 50 communes in the province.

Our evaluation is based on the randomized introduction of the pilot scheme using follow-up data only. We could not collect proper baseline data before the roll-out of the pilot, because we started collaborating with the LEAP team only shortly before the launch of the project. We had planned a larger RCT with baseline data (using a more extensive household survey and also behavioral games), but the larger project did not continue as planned due to reasons beyond the scope of our involvement (see footnote 1 for details). Therefore, we were only able to evaluate the pilot scheme with follow-up data. We examine balancing success in terms of a large array of plausibly pre-determined commune, village, household and individual variables (as explained in more detail below). Since we did not have a pre-analysis plan in place nor preregister, which was uncommon in the field at the time, ${ }^{12}$ this is an exploratory type of analysis. Finally, there were no power calculations performed for this pilot study.

The randomization and sampling strategy are summarized in Fig. 2. To evaluate a causal effect of the project, we randomly selected 6 communes to receive the LEAP pilot. All 18 villages in the 6 treated pilot communes were treated and also surveyed. In addition, we randomly sampled 18 villages from 18 randomly selected control communes. This is an intent-totreat design: the program was not offered in control communes and within treated communes the program was offered but participation was voluntary. In each of the 36 villages (18 treated, 18 control), we aimed to survey 15 households. Since this is an intent-to-treat design, our sample from the treated villages contains both SHG members and residents who elected not to participate in the program.

We used earlier census and sampling lists with household names for each village to reach a total of 540 households. LEAP targeted poor households, those that were officially classified as IDPoor-1 and IDPoor-2. However, the success of targeting is ultimately an empirical question. To explore effects across the poor and non-poor, we randomly sampled five households from each of the three official, poverty groups (IDPoor 1, IDPoor 2, Non-Poor). We had to sample 85 substitute households (42 control, 43 treated) since not all initially chosen households could be surveyed. Substitute households are balanced by treatment status as can be seen in column 1 of Table 2, where we regress missingness on a LEAP dummy, as well as an interaction term between LEAP and being a non-poor household (see Section 4.5 for details on the empirical models including average effects and p-value calculation). The effect associated with the variable LEAP is the main point estimate of interest, showing impacts concentrated in the targeted group (IDPoor 1 and IDPoor 2). The additional effect among the Non-poor is captured by the term LEAP $x$ Non-poor. Column 1 shows that the treatment effect on the likelihood of being

\footnotetext{
10 The subjects were told that the money would be left with their chief to be picked up in a week. We were aware that subjects may have had different levels of trust in their chief. As with the gambling variable this measure was not a main focus of our analysis, but included only as a possible confound or
} 


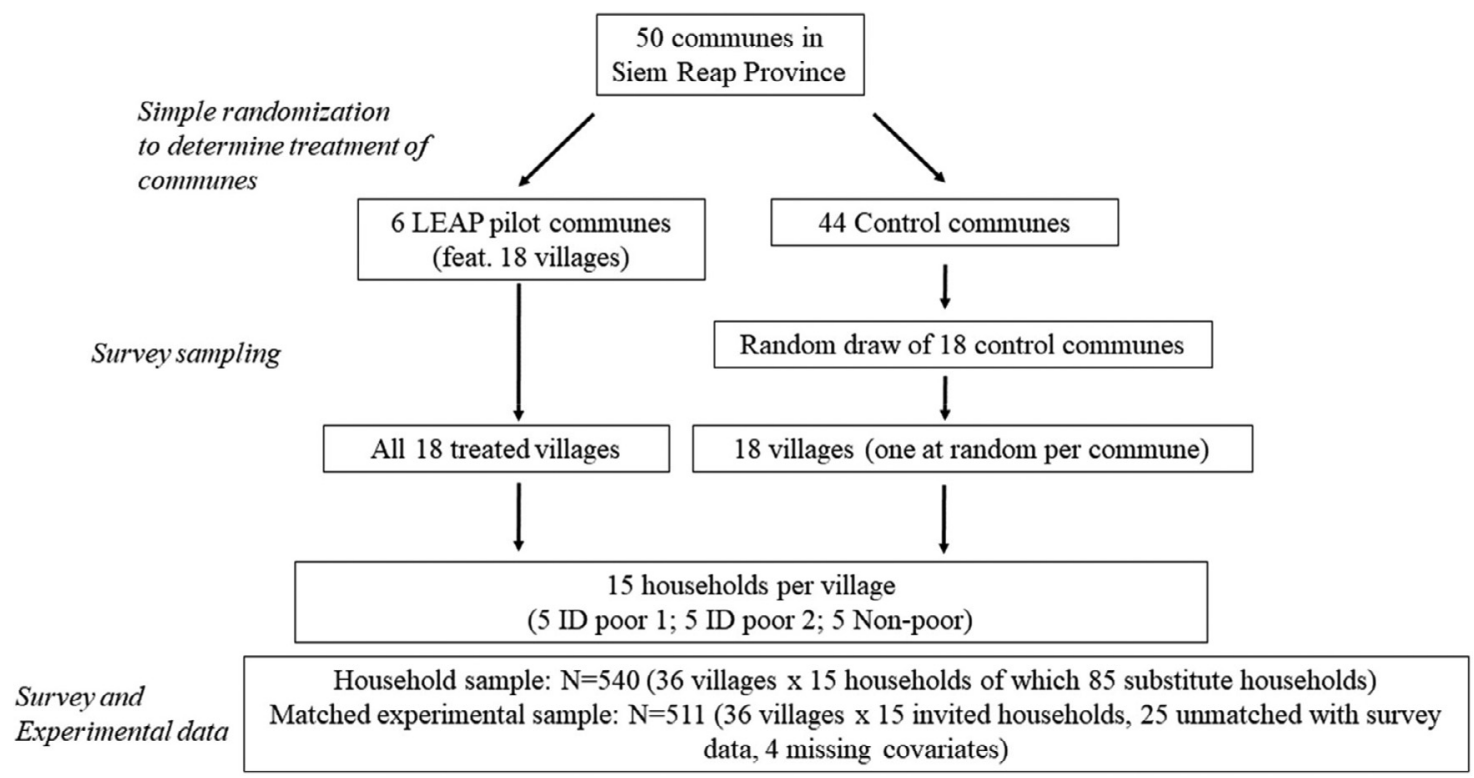

Fig. 2. Randomization and Sampling Strategy.

Table 2

Missingness.

\begin{tabular}{llll}
\hline & $(1)$ & $(2)$ & $(3)$ \\
& Substitute survey household & Missing household from experimental session (but in survey) \\
\hline Mean poor control households & 0.160 & 0.039 & 0.099 \\
LEAP & 0.030 & 0.023 & 0.321 \\
Wild boot. p-value & 0.471 & 0.471 \\
Q-value & 0.471 & 0.471 & -0.035 \\
LEAP x Non-poor household & -0.077 & 0.478 \\
Wild boot. p-value & 0.352 & 0.478 \\
Q-value & 0.478 & 0.006 \\
Non-poor household & -0.014 & 0.765 \\
Wild boot. p-value & 0.823 & 0.823 \\
Q-value & 0.823 & 540
\end{tabular}

Note: Wildbootstrap clustered at the commune level (24), 10,000 replications. Q-values controlling for the False Discovery Rate (FDR) as suggested by Anderson (2008) were calculated by row using the STATA do-file by Michael L. Anderson, available at: http://are.berkeley.edu/ mlanderson/downloads/ fdr_qvalues.do.zip. [Accessed May 25, 2017].

a poor substitute household amounts to an insignificant 3\%-points. The additional effect of being non-poor is negative and offsets the positive LEAP effect.

The household survey team gave each household an invitation to send a primary adult (mostly females) to a laboratory session on a later day in that village. After the household survey had passed through the village, the second team organized these laboratory sessions in the village. 526 households participated in these sessions. We did not sample substitute households for the experimental sessions to stay consistent with the household survey sample. In addition, we were not always able to match the household with the experimental session data (11 such cases in control, 14 in treated areas). The likelihood of missing households from the experimental session is thus very similar in treated and control villages (the difference is a mere 2.3\%-points comparing IDPoor treated and untreated individuals), and as such the few missing households should not bias our main findings (see column 2, Table 2). In four matched cases balancing covariates are missing. The final analysis sample for behavioral outcomes consists of 511 households. Some further observations are missing for specific games (14 in the discount rate game, 1 in the public good game).

operating mechanism for social preferences. As we show below, patience was uncorrelated with the treatment and with interpersonal trust, so this should not be a concern.

${ }^{11}$ In a robustness check reported in section 5.5, we find no evidence that initial winnings (in the lottery activity) correlate with subsequent pro-social behavior.

${ }^{12}$ For instance, the AEA's trial registry was only launched around 2013. See here: https://blogs.worldbank.org/impactevaluations/ trying-out-new-trial-registries [Accessed January 20, 2020] 
Table 3

Balancing Tests.

\begin{tabular}{|c|c|c|c|c|c|c|c|}
\hline & \multirow[t]{2}{*}{$\mathrm{N}$} & \multirow[t]{2}{*}{ Mean } & \multirow[t]{2}{*}{ SD } & \multicolumn{2}{|l|}{ Mean } & \multicolumn{2}{|l|}{ Diff. } \\
\hline & & & & Control & LEAP & P-value & Q-value \\
\hline \multicolumn{8}{|l|}{ Commune characteristics } \\
\hline Nr. of households (in $100 \mathrm{~s}$ ) & 24 & 13.23 & 6.17 & 12.21 & 16.31 & 0.16 & 0.33 \\
\hline Fraction of poor households (ID 1 \& 2) & 24 & 0.30 & 0.09 & 0.31 & 0.28 & 0.49 & 0.49 \\
\hline \multicolumn{8}{|l|}{ Village characteristics } \\
\hline Total population (in $100 \mathrm{~s}$ ) & 36 & 8.33 & 4.03 & 8.54 & 8.45 & 0.76 & 0.89 \\
\hline Nr. of households & 36 & 174.08 & 84.63 & 178.94 & 169.22 & 0.74 & 0.89 \\
\hline Fraction of households female headed & 36 & 0.27 & 0.16 & 0.27 & 0.29 & 0.81 & 0.89 \\
\hline Male literacy rate ( $>15$ years) & 36 & 0.74 & 0.16 & 0.73 & 0.77 & 0.66 & 0.89 \\
\hline Female literacy rate ( $>15$ years) & 36 & 0.58 & 0.20 & 0.58 & 0.65 & 0.89 & 0.89 \\
\hline Dependency ratio & 36 & 0.66 & 0.12 & 0.68 & 0.66 & 0.44 & 0.89 \\
\hline \multicolumn{8}{|l|}{ Household characteristics } \\
\hline Female headed household (binary) & 540 & 0.31 & & 0.30 & 0.31 & 0.83 & 0.89 \\
\hline Age of household head & 540 & 46.38 & 13.71 & 46.26 & 46.50 & 0.89 & 0.89 \\
\hline Literate household head (binary) & 540 & 0.52 & & 0.51 & 0.53 & 0.75 & 0.89 \\
\hline Highest completed school primary 6+ (binary) & 540 & 0.13 & & 0.14 & 0.12 & 0.49 & 0.89 \\
\hline Head has always lived in the village & 540 & 0.69 & & 0.68 & 0.71 & 0.60 & 0.89 \\
\hline Head is married (binary) & 540 & 0.70 & & 0.73 & 0.67 & 0.21 & 0.89 \\
\hline Household size & 540 & 4.80 & 1.92 & 4.86 & 4.74 & 0.48 & 0.89 \\
\hline Average age of household members & 540 & 28.88 & 12.61 & 28.73 & 29.03 & 0.84 & 0.89 \\
\hline Owns land on which house is built (with documents, binary) & 540 & 0.39 & & 0.33 & 0.44 & 0.13 & 0.89 \\
\hline Cultivates inherited land (binary) & 540 & 0.74 & & 0.72 & 0.76 & 0.64 & 0.89 \\
\hline \multicolumn{8}{|c|}{ Experimental participant characteristics (matched with household survey) } \\
\hline Male (binary) & 511 & 0.16 & & 0.16 & 0.16 & 0.98 & 0.98 \\
\hline Age & 511 & 42.26 & 14.30 & 42.33 & 42.18 & 0.93 & 0.98 \\
\hline Education (in years) & 511 & 2.65 & 2.98 & 2.75 & 2.56 & 0.68 & 0.98 \\
\hline Married (binary) & 511 & 0.72 & & 0.73 & 0.71 & 0.76 & 0.98 \\
\hline \multicolumn{8}{|l|}{ Additional balancing tests } \\
\hline \multicolumn{8}{|l|}{ Nr. of links to the other experimental participants (max. 14) } \\
\hline Family & 511 & 3.23 & 3.64 & 2.17 & 4.30 & 0.08 & 0.23 \\
\hline Neighbor & 511 & 1.66 & 1.90 & 1.52 & 1.80 & 0.67 & 0.76 \\
\hline Krum (administrative unit, below Village) & 511 & 1.27 & 1.91 & 1.19 & 1.35 & 0.76 & 0.76 \\
\hline
\end{tabular}

Note: Standard p-values for comparisons of commune characteristics. All other comparisons, wildbootstrap clustered p-values at the commune level (24), 10,000 replications. Q-values controlling for the False Discovery Rate (FDR) as suggested by Anderson (2008) were calculated by families of indicators in italics (commune, village, household survey, experiment, additional) using the STATA do-file by Michael L. Anderson, available at: http://are.berkeley.edu/ mlanderson/downloads/fdr_qvalues.do.zip. [Accessed May 25 2017].

Our survey coverage was sufficient to reach enough treated households, in part because we oversampled ID Poor households. According to the 2008 poverty census there were 9785 households in LEAP communes. The LEAP program reports having 1291 members, for a maximum coverage rate (assuming one SHG member per household) of about 13\%. In our survey, $28 \%$ of control communities' households were SHG members and $54 \%$ of treated community households were SHG members. Since the treatment was randomized the most plausible explanation for the 26-point difference is the LEAP program. The increase in SHG membership is larger in our survey sample than in LEAP program documentation due to our intentional oversampling of ID poor households.

The program clearly failed to target poor people exclusively. $47 \%$ of non-poor people were members of SHGs in treated areas, compared to $26 \%$ in control areas, for a difference of 21 points. That non-poor benefitted from the program is also apparent in the regression estimates in Section 5: although point estimates generally indicate that non-poor benefitted less than the poor these estimates are rarely statistically significant, suggesting that poor and non-poor participated in and benefitted from the program indistinguishably in our relatively small sample.

\subsection{Balance, descriptive statistics and representativeness}

To demonstrate the validity of our identification strategy, we present randomization checks in Table 3 . To that end, we use our survey data and complement that with the country's 2008 village census of the area (part of the national census and provided to us by the National Institute of Statistics of Cambodia, see also Kingdom of Cambodia, 2008). In the case of household and individual comparisons, $p$-values in Table 3 are wild bootstrapped clustering at the commune level due the small number of 24 clusters. Specifically, we use STATA's boottest with 10,000 replications provided by Roodman et al., (2019). Due to multiple hypothesis testing concerns, we also report associated q-values controlling for the False Discovery Rate (FDR) by family of indicators as suggested by Anderson (2008). 
Table 4

Primary Occupations.

\begin{tabular}{|c|c|c|c|}
\hline Primary occupation of household head & Control & Treatment & Total \\
\hline Rice farming & 87 & 82 & 169 \\
\hline Small business & 38 & 25 & 63 \\
\hline Construction work & 29 & 28 & 57 \\
\hline On-farm wage labor & 24 & 18 & 42 \\
\hline Fishing & 13 & 19 & 32 \\
\hline Off-farm wage labor & 14 & 16 & 30 \\
\hline Salary work & 7 & 19 & 26 \\
\hline Dependence & 11 & 10 & 21 \\
\hline Livestock raising & 12 & 7 & 19 \\
\hline Not working person & 10 & 7 & 17 \\
\hline Handicraft & 4 & 12 & 16 \\
\hline Vegetable farming & 5 & 10 & 15 \\
\hline Chamkar & 5 & 4 & 9 \\
\hline Other categories & 11 & 13 & 24 \\
\hline Total & 270 & 270 & 540 \\
\hline
\end{tabular}

Overall, treatment status is statistically insignificant at conventional levels for a large array of commune, village and household level variables (see Table 3). Among the aggregate statistics one is worth mentioning in more detail. The number of people and households in a village is well-balanced, which is re-assuring given that we sampled a fixed number (15) of households per village. Control villages have just 9 households more (5.7\% difference) on average (treated 178.94 households vs. control 169.22 households). The difference is highly insignificant ( $p$-value $=0.74, q$-value $=0.89$ ).

What are the basic characteristics and living conditions of households in our sample? Thirty-one percent of household heads are female and $52 \%$ of heads are literate. $69 \%$ of heads have always lived in their current village. Average household size is 4.8 . Further, $39 \%$ of households can document that they own the land on which their house is built and $74 \%$ cultivate inherited land. Across-the-board differences in these household characteristics between treatment and control areas are statistically insignificant.

The lower part of Table 3 shows characteristics of our experimental participants. Most of them are female (as prioritized ${ }^{13}$ by the intervention and survey teams), married and have less than three years of education. Subjects in the laboratory sessions average 3.23 family links with the other 14 participants in their session. There is some experimental imbalance in that participants in treated villages have double the amount of family links $(\Delta 2.13, p$-value $=0.08, q$-value $=0.23)$. This imbalance may influence behavior in the lab-in-the field experiments, so we will discuss in the results section what happens to our unconditional findings once we control for the number of family links. Other variables are reasonably well-balanced across treatment and control. In other words, there is no apparent self-selection of participants as a function of treatment.

How representative is our sample? We can compare our sample of villages to the potential target villages identified by the government in Siem Reap Province. Table A1 shows that our sampled (and pilot intervention) villages are very similar in terms of population characteristics and education levels as well as female empowerment (proportion of female household heads and literacy) to the larger set of villages. The same table also gives available national indicators from the 2008 Cambodian census. Of note is that our intervention area is lagging behind national averages when it comes to literacy rates (Kingdom of Cambodia, 2008). We find that average household size and the proportion of female headed households is similar. Overall, these patterns suggest that our small survey and experimental sample is well in line with the characteristics of the target population.

\subsection{Social context: clues from control communities}

In what follows we describe the social context of our study area and population to help situate our subsequent findings. We present averages in the control group as a pseudo-baseline in the absence of proper baseline data. The primary occupations of household heads are exhibited in Table 4. Rice farming is clearly the predominant main occupation (both in treated and control households), followed by small business ownership, construction work, on-farm wage labor, and fishing. Table 5 provides descriptive statistics of the outcome variables from the household survey used in the impact evaluation. Like in the subsequent analysis, we have grouped them into group memberships, savings, borrowing, production, assets, expenditure, and community action variables. If variable definitions are not self-explanatory, further definitions can be found in Table A2.

$28 \%$ of control households have at least one member in a SHG while $21 \%$ and $20 \%$ of households feature at least one member in a rice seed and a women's group, respectively. Thus, the types of groups created and encouraged by LEAP preexisted in control communes. Other organizations established self-help groups in Siem Reap prior to LEAP's involvement in the area. Conversely, membership in the remaining groups is relatively low: Few control households are members of producer, funeral/death and irrigation associations.

\footnotetext{
13 Men were however not excluded.
} 
Table 5

Survey Outcomes.

\begin{tabular}{|c|c|c|c|c|c|c|}
\hline & \multirow[t]{2}{*}{ Mean } & \multirow[t]{2}{*}{ SD } & \multicolumn{2}{|l|}{ Mean } & \multicolumn{2}{|l|}{ Diff. } \\
\hline & & & Control & LEAP & P-value & Q-value \\
\hline \multicolumn{7}{|l|}{ Group memberships } \\
\hline \multicolumn{7}{|l|}{ Household is member in the following community groups (all binary): } \\
\hline Self-help-group (SHG) & 0.41 & & 0.28 & 0.54 & 0.00 & 0.00 \\
\hline Producer association & 0.04 & & 0.03 & 0.06 & 0.22 & 0.26 \\
\hline Rice seed association & 0.34 & & 0.21 & 0.46 & 0.00 & 0.00 \\
\hline Death association & 0.09 & & 0.12 & 0.06 & 0.23 & 0.26 \\
\hline Youth association & 0.05 & & 0.03 & 0.06 & 0.12 & 0.22 \\
\hline Irrigation association & 0.04 & & 0.02 & 0.05 & 0.09 & 0.21 \\
\hline Women association & 0.26 & & 0.20 & 0.32 & 0.40 & 0.40 \\
\hline \multicolumn{7}{|l|}{ Current savings (with MFIs, SHGs, lenders, friends/relatives, other) } \\
\hline Household currently has non zero savings (binary) & 0.33 & & 0.22 & 0.44 & 0.00 & 0.00 \\
\hline Total current household savings (in 1000s riel) & 141.96 & 1200.14 & 151.36 & 132.56 & 0.86 & 0.86 \\
\hline$\ldots$. in $\log$ (inverse hyperbolic sine transformed) & 1.49 & 2.29 & 1.01 & 1.98 & 0.00 & 0.00 \\
\hline \multicolumn{7}{|l|}{ Borrowing (any household member, all binary) } \\
\hline \multicolumn{7}{|l|}{ Can the household borrow now from: } \\
\hline Self-help-group (SHG) & 0.35 & & 0.25 & 0.46 & 0.00 & 0.02 \\
\hline Friend & 0.71 & & 0.70 & 0.72 & 0.76 & 0.76 \\
\hline Bank & 0.13 & & 0.10 & 0.16 & 0.09 & 0.27 \\
\hline Applied for a loan at financial institutions/informal/SHG, over the last year & 0.62 & & 0.63 & 0.60 & 0.62 & 0.74 \\
\hline Received a loan from financial institutions/informal/SHG, last year (2012) & 0.61 & & 0.63 & 0.59 & 0.37 & 0.63 \\
\hline Ever applied for loan at formal financial institutions/informal/SHG & 0.68 & & 0.70 & 0.67 & 0.42 & 0.63 \\
\hline \multicolumn{7}{|l|}{ Household production (see appendix for precise definitions) } \\
\hline Annual livestock production per capita, last one year (in 1000s riel) & 316.65 & 660.87 & 241.09 & 392.21 & 0.13 & 0.14 \\
\hline Annual income from livestock sales per capita, last one year (in 1000s riel) & 230.60 & 594.93 & 164.70 & 296.49 & 0.14 & 0.14 \\
\hline Annual income from crop sales per capita, 2012 harvest season (in 1000s riel) & 115.44 & 290.34 & 146.15 & 84.74 & 0.13 & 0.14 \\
\hline Other annual revenue-generating activities per capita, 2012 (in 1000s riel) & 1376.35 & 2587.13 & 1614.06 & 1138.65 & 0.08 & 0.14 \\
\hline \multicolumn{7}{|l|}{ Household assets (see appendix for precise definitions) } \\
\hline Assets per capita (in 1000 s riel) & 590.11 & 2029.63 & 820.52 & 359.71 & 0.00 & 0.01 \\
\hline Livestock holdings per capita, current (in 1000s riel) & 442.10 & 2007.68 & 356.67 & 527.52 & 0.57 & 0.72 \\
\hline Livestock acquired (total number), over last one year & 1.00 & 3.04 & 0.94 & 1.06 & 0.72 & 0.72 \\
\hline \multicolumn{7}{|l|}{ Household expenditures (see appendix for precise definitions) } \\
\hline Non-food expenditures per capita, past 30 days (in 1000 s riel) & 25.15 & 31.96 & 25.61 & 24.69 & 0.79 & 0.79 \\
\hline Misc. expenditures per capita, past 12 months (in 1000s riel) & 461.18 & 665.46 & 485.96 & 436.40 & 0.47 & 0.71 \\
\hline Bought food consumption per capita, past 7 days (in $100 \mathrm{~s}$ riel) & 157.23 & 197.50 & 167.82 & 146.64 & 0.44 & 0.71 \\
\hline \multicolumn{7}{|l|}{ Community action } \\
\hline Number of community meetings attended over the last year & 7.28 & 6.38 & 6.37 & 8.18 & 0.02 & 0.07 \\
\hline \multicolumn{7}{|l|}{ Household member helped, past 6 months (all binary): } \\
\hline Build or rebuild school & 0.36 & & 0.36 & 0.35 & 0.96 & 0.98 \\
\hline Build or repair road & 0.60 & & 0.60 & 0.60 & 0.98 & 0.98 \\
\hline Clean up public space in the community & 0.26 & & 0.24 & 0.28 & 0.62 & 0.98 \\
\hline
\end{tabular}

Note: $N=540$. P-values are wildbootstrap clustered at the commune level (24), 10,000 replications. $Q$-values controlling for the False Discovery Rate (FDR) as suggested by Anderson (2008) were calculated by families of indicators in italics (demarcated by horizontal borders) using the STATA do-file by Michael L. Anderson, available at: http://are.berkeley.edu/ mlanderson/downloads/fdr_qvalues.do.zip. [Accessed May 25 2017].

1 USD 4000 Cambodian Riel.

Consider next the savings and borrowing indicators (some primary target outcomes of the LEAP project): it is worth underlining that merely $22 \%$ of households in control areas have non-zero savings. The average amount of savings is therefore low (151,360 riel or 37 USD) and highly skewed. Given the prevalence and importance of non-zero saving in Siem Reap province, we examine the program impact on the likelihood of non-zero savings (which was large) in our subsequent analysis. Additionally, we report various transformations of the relatively "misbehaving" savings variables (winsorizing and inverse hyperbolic sine transformation). One-fourth of control households report being able to borrow from SHGs, $63 \%$ have applied for a loan over the last year and $63 \%$ obtained a loan in $2012.70 \%$ of respondents have at least once applied for loans in the past.

Moving on to the economic situation of control households: Annual income from livestock sales per capita over the last one year was 164,700 riel (about 40 USD); assets per capita amount to 820,520 riel (about 200 USD); miscellaneous expenditures per capita over the past 12 months were 485,960 riel (about 199 USD), while bought-food consumption per capita over the last seven days prior to enumeration was 16,782 riel (about 4 USD). Finally, community action is an important dimension of any grass-roots intervention. The average control household attended 6.37 community meetings over the last year. Most households report concrete community action: 36\% and 60\% of control households report having helped 
Table 6

Experimental Session Outcomes.

\begin{tabular}{|c|c|c|c|c|c|c|c|}
\hline & \multirow[t]{2}{*}{$\mathrm{N}$} & \multirow[t]{2}{*}{ Mean } & \multirow[t]{2}{*}{ SD } & \multicolumn{2}{|l|}{ Mean } & \multicolumn{2}{|l|}{ Diff. } \\
\hline & & & & Control & LEAP & P-value & Q-value \\
\hline Risk taking $[1=$ low $-5=$ high $]$ & 511 & 2.24 & 1.04 & 2.18 & 2.30 & 0.42 & 0.83 \\
\hline Impatience [ $1=$ very patient $-6=$ very impatient] & 497 & 3.41 & 2.38 & 3.38 & 3.44 & 0.86 & 0.86 \\
\hline Altruism (amount sent in dictator game, $0-3000$ riel) & 511 & 766.14 & 569.32 & 732.56 & 800.40 & 0.16 & 0.65 \\
\hline Public good contribution (yes $=1$, no $=0$ ) & 510 & 0.67 & & 0.65 & 0.69 & 0.44 & 0.71 \\
\hline Trust (amount sent in the trust game, $0-3000$ riel) & 243 & 633.74 & 650.50 & 597.56 & 670.83 & 0.57 & 0.71 \\
\hline Trustworthiness (fraction returned in the trust game) & 266 & 0.15 & 0.14 & 0.15 & 0.16 & 0.71 & 0.71 \\
\hline \multicolumn{8}{|l|}{ Nr. of links to the other experimental participants (max. 14): } \\
\hline \multicolumn{8}{|l|}{ SHG/Savings Networks } \\
\hline Self-help-group (nr. of links) & 511 & 0.48 & 1.52 & 0.11 & 0.85 & 0.09 & 0.09 \\
\hline Savings group (nr. of links) & 511 & 0.50 & 1.66 & 0.07 & 0.95 & 0.05 & 0.09 \\
\hline \multicolumn{8}{|l|}{ Economic Networks } \\
\hline Funeral group ( $1=$ having at least one link, 0 otherwise) & 511 & 0.11 & & 0.02 & 0.19 & 0.31 & 0.92 \\
\hline Exchange hands (for free, nr. of links) & 511 & 3.53 & 4.49 & 2.48 & 4.60 & 0.15 & 0.90 \\
\hline Regular buying and selling link (undirected, nr. of links) & 511 & 3.23 & 3.99 & 3.06 & 3.40 & 0.78 & 0.93 \\
\hline Employee-relationship (undirected, nr. of links) & 511 & 1.61 & 2.79 & 1.64 & 1.57 & 0.93 & 0.93 \\
\hline Coworker (nr. of links) & 511 & 2.53 & 3.73 & 2.64 & 2.42 & 0.83 & 0.93 \\
\hline Producer group ( $1=$ having at least one link, 0 otherwise) & 511 & 0.02 & & 0.00 & 0.04 & 0.46 & 0.92 \\
\hline \multicolumn{8}{|l|}{ Social Networks } \\
\hline Worhsip group (nr. of links) & 511 & 2.14 & 4.23 & 1.46 & 2.83 & 0.34 & 0.85 \\
\hline Babysitting (nr. of links) & 511 & 0.39 & 0.87 & 0.39 & 0.40 & 0.94 & 0.94 \\
\hline Seek advice (nr. of links) & 511 & 0.92 & 1.51 & 0.75 & 1.10 & 0.38 & 0.85 \\
\hline Social Group (nr. of links) & 511 & 3.18 & 4.08 & 2.70 & 3.67 & 0.54 & 0.85 \\
\hline Volunteering (nr. of links) & 511 & 2.17 & 3.71 & 2.05 & 2.30 & 0.81 & 0.94 \\
\hline Borrow (non monetary, nr. of links) & 511 & 1.67 & 2.77 & 1.36 & 1.98 & 0.56 & 0.85 \\
\hline
\end{tabular}

Note: P-values are wildbootstrap clustered at the commune level (24), 10,000 replications. Q-values controlling for the False Discovery Rate (FDR) as suggested by Anderson (2008) were calculated by families of indicators in italics (demarcated by horizontal borders) using the STATA do-file by Michael L. Anderson, available at: http://are.berkeley.edu/ mlanderson/downloads/fdr_qvalues.do.zip. [Accessed May 25 2017].

1 USD $~ 4000$ Cambodian Riel.

repair/build a school and road, respectively and $24 \%$ of households claim to have cleaned up public spaces over the same time horizon.

Behavior in the games and network measures are reported in Table 6. Again, it is useful to consider the means in the control group in the absence of baseline data. In the altruism game, control households sent $24 \%$ of their endowment to a poor anonymous family in the village (733 out of 3000 riel). This amount is quite close to previous studies: in a metaanalysis Engel (2011) found that the average give rate was about $28 \% .65 \%$ of subjects contributed in the dichotomous public good game. We could not find a meta-analysis of dichotomous public goods games. In a meta-analysis of linear public goods games subjects contributed about 38\% of their endowment (Zellmer 2003). Barrett (2005) on whom this game is based reports that in the many cases and contexts in which he conducted this game, one- to two-third of the participants contribute. Our results are near the very high end of that range.

The trust game tells a different story, however, control group investors in the trust game sent on average $20 \%$ (598 out of 3000 riel). In comparison, a meta study by Johnson and Mislin (2011) of more than 200 trust games conducted around the globe indicates that subjects typically sent about 50\%. Thus, our subject pool displays lower levels of trust, so, in principle, there is room for LEAP to improve trust. Consistent with the low levels of trust, control subjects returned only about $15 \%$ of the total amount available compared to the common one-third in the rest of the world as reported by Johnson and Mislin (2011). Thus, subjects in this experiment returned only about half of what has been observed on average in the past. This lack of trustworthiness can help explain the similarly low levels sent in the first round of the trust game. It appears that the communities in which we worked possessed relatively weak norms of trustworthiness, which in turn support relatively low levels of trust at least as measured in our games. Our trust game findings are similar to those from five Cambodia villages reported by Weingart and Kirk (2012).

Finally, consider the number of network links to other members in the experimental session. Most relevant, the links to other self-help and savings group members averaged well below one in control communities (out of a possible maximum number of 14 links). Participants did know about 2-3 other participants from exchange of hands or economic trades, respectively. Links via funeral group networks are rare and skewed in control units (for that reason we work with a binarized network variable capturing at least one or more link). Just $2 \%$ have at least one such link. The same is true for producer groups links, which we also binarize. Here the mean in the control group is zero links. Among further social networks, links via social groups and volunteering ( $>2$ links each) stand out. 


\subsection{Empirical model}

We will present simple regression-based differences-in-means between treated and control villages, differentiating by the poverty status of households. Recall, LEAP targeted households that were officially classified as poor beforehand (IDPoor 1 and IDPoor 2). Our data features four groups of households: poor ones living in a treated area, non-poor ones living in a treated area, poor ones living in a control area, non-poor ones living in a control area. In each village we sampled 10 poor and 5 non-poor households. Our model is specified to capture all this: a point estimate associated with the LEAP indicator is the effect on the poor compared to the poor in control areas, our main comparison of interest. An interaction term denoted LEAP $\times$ non-poor household indicates the additional treatment effect (negative or positive) on the non-poor. And a Non-poor household indicator by itself shows differences between poor and non-poor households in control areas.

Throughout the analysis, all standard errors are clustered at the commune or treatment level $(N=24)$. Due to the small number of clusters, we only provide wild bootstrapped p-values with 10,000 replications in all tables (see Cameron et al., 2008, MacKinnon and Webb 2017a; we use the boottest command in STATA by Roodman et al., 2019). One caveat to acknowledge is that we have fewer treated than control communes (clusters). And treated clusters feature more observations, as the same number of households are included in treatment and control overall. This may lead to wild bootstrapped p-values that are too low and leading us in turn to "overreject" (see MacKinnon and Webb, 2018, 2017b).

Further, we report q-values controlling for the False Discovery Rate (FDR) for each table's row of estimates as proposed by Anderson (2008). Finally, each table also shows average, standardized effects following Kling et al. (2004) and Clingingsmith et al. (2009). To that end, effects across indicators are estimated jointly in a seemingly unrelated regression framework allowing for cross-error correlation. Effects are then standardized (in the case of LEAP by the standard deviation of outcomes among the IDPoor in the control villages; in the case of LEAP $x$ Non-poor household by the standard deviation of outcomes among the Non-Poor in the control villages) and the average effect is calculated. Each standardized effect comes with a wild bootstrapped p-value. Looking at the average effect reduces the danger of singling out significant results that arise by chance and provides an overall effect for each group of indicators. One way to gauge the distributional magnitude of the average effect is to apply a Cohen (1988)'s D interpretation where (absolute) effects equate to $0.2=$ Small, $0.5=$ Medium and $0.8=$ Large. Do note that these cut-offs are arbitrary and economic magnitudes may differ across fields and types of interventions; still it is a useful benchmark.

\section{Results}

In what follows, we report effects by groups of indicators. The main effect of interest is the one associated with the LEAP treatment dummy, which shows the program's effect on poor households. We streamline our discussion in the following way. First, we always discuss the respective average effect (presented in the last column of each table). We use Cohen's D cut-offs to evaluate if average effects are sizable or not. Throughout we clearly mention if we are under-powered for a group of indicators or not based on that measure. Second, we discuss the individual effects along with p- and q-values. For individual effects we relate to the poor household's means in the control group to judge economic magnitudes and mention possible power issues. Third, we comment on interaction effects of LEAP with the Non-poor household indicator throughout.

\subsection{Self-help group (SHG) membership}

Before discussing the socio-economic impacts of LEAP, it is vital to examine whether LEAP caused the desired increase in SHG membership. Other organizations besides LEAP were fostering self-help groups in Siem Reap, so we need to establish that LEAP caused an increase in self-help group membership over and above what other programs would have accomplished. Table 7's last column reports a large (Cohen's $D>0.8)$ and significant average effect of $1.112(p$-value $=0.002)$ across two SHG indicators among poor households (self-help group membership and number of links to the other experimental participants via a self-help group, max. 14 links). The average interaction effect is close to a medium Cohen's D and negative, indicating reduced impacts on the non-poor (who were not targeted by the program), but we lack power to precisely estimate the differential effect ( $p$-value=0.323). Moving to the individual effects, column 1 suggests a $28.8 \%$-point increase in the probability that a poor household residing in a treatment area features at least one member in a SHG. This represents a doubling of SHG membership over the $28.7 \%$ in the control group (poor households in control villages). The effect is highly significant as judged by the wild bootstrapped $p$-value $(0.003)$ and associated $q$-value $(0.006)$. The interaction term with the non-poor indicator is negative and moderate in size $(-7.4 \%$-points $)$ as one would expect from a program that targeted the poor, yet it is highly insignificant ( $p$-value $/ q$-value $=0.592$ ). For illustration, LEAP's effect on the non-poor is thus $0.288-0.074=0.214(p$ value $=0.090$, unreported in table). Column 2 indicates that poor experimental participants residing in treated areas report on average 0.849 more links to co-members in SHGs in the network survey, which constitutes a massive seven-fold increase relative to the 0.127 average links reported in the poor control group. The interaction term is again negative, as would be expected from a program that targeted the poor, but it is highly insignificant $(-0.294, p$-value $=0.402, q$-value $=0.592)$.

In sum, since LEAP has successfully expanded SHG membership and networks in treated areas it is not unreasonable to expect the broader socio-economic impacts that we explore in the following sections. 
Table 7

SHG Outcomes.

\begin{tabular}{lll}
\hline & $\begin{array}{l}(1) \\
\text { At least one household member is in a } \\
\text { self-help group (binary) }\end{array}$ & $\begin{array}{l}\text { (2) of links to the other experimental } \\
\text { pr. } \\
\text { participants in a self-help group (max. 14) }\end{array}$ \\
\hline $\begin{array}{l}\text { Mean poor control } \\
\text { households }\end{array}$ & 0.287 & 0.127 \\
LEAP & 0.288 & 0.849 \\
Wild boot. p-value & 0.003 & 0.057 \\
Q-value & 0.006 & 0.057 \\
LEAP x Non-poor household & -0.074 & -0.294 \\
Wild boot. p-value & 0.592 & 0.402 \\
Q-value & 0.592 & 0.592 \\
Non-poor household & -0.029 & -0.057 \\
Wild boot. p-value & 0.69 & 0.583 \\
Q-value & 0.69 & 0.69 \\
N & 540 & 511
\end{tabular}

Note: Wildbootstrap clustered at the commune level (24), 10,000 replications. Q-values controlling for the False Discovery Rate (FDR) as suggested by Anderson (2008) were calculated by row using the STATA do-file by Michael L. Anderson, available at: http://are.berkeley.edu/ mlanderson/downloads/ fdr_qvalues.do.zip. [Accessed May 25 2017].

\subsection{Savings and borrowing}

The effects of the program on savings and borrowing ability - an important outcome for the project - are reported in Table 8. The average effect of LEAP on savings outcomes among the poor in the final column points to a medium-sized Cohen's D across all six savings outcomes $(0.547, p$-value $=0.095)$. The average effect among the non-poor is small and almost half the size, the interaction term is -0.231 , but this heterogeneity is just about insignificant $(p$-value $=0.102)$. The individual regressions paint a similar picture: Column 1 reports the effect of the program on the probability of non-zero savings, an important indicator in the LEAP program area where many households have no savings at all. LEAP increased the likelihood of having some savings among the poor by $28.2 \%$-points with both $p$ - and $q$-values well below the $5 \%$ threshold of significance. In comparison, a mere $19.9 \%$ of poor households in control areas have savings, so this constitutes a more than doubling of households with some savings. As expected and given the program's pro-poor intentions, the impact on nonpoor households is smaller: non-poor households in treated areas are 10.5\%-points more likely to have non-zero savings than those residing in control areas (0.282-0.177), but this difference is only suggestive since it is imprecisely estimated ( $p$-value $=0.17, q$-value $=0.427$ ). The impact on actual savings is also positive and significant in column $2: 1.2$ higher than the control mean and amounting to 30,037 riel or 7.5 USD at the time ( $p$-value $/ q$-value $=0.082$ ). Column 3 reports similar patterns after "winsorizing" savings to account for outliers (0.1;0.9 percentiles), suggesting a 1.8 increase over the control mean ( $p$-value $=0.006, q$-value $=0.011)$. In both cases (columns 2 and 3$)$, the interaction effect between the Non-poor indicator and LEAP is negative and sizeable relative to the main treatment effect, however highly insignificant. Column 4 shows impacts on per capita savings of 8167 Cambodian riels ( $p$-value $=0.004, q$-value $=0.011$ ), a meaningful increase relative to the controlvillage mean (5347 riels). Column 5 employs a "log-like" inverse hyperbolic sine transformation suitable in the presence of zeroes and outliers. Point estimates can be interpreted like a log-specification. Similar patterns emerge - sizeable effects on the poor's savings and smaller effects on the non-poor's savings (though the interaction term is not precisely estimated). To put the above patterns in a broader economic perspective it is useful to consider column 6 where we scale total savings by total annual household production. LEAP increased this proportion by 4.1 points over the 2.2 points observed in the control group $(p$-value $=0.019, q$-value $=0.023)$.

Finally, column 7 looks at borrowing ability. ${ }^{14}$ Poor respondents in treated areas are $23.2 \%$-points more likely to report that they have the ability to borrow from an SHG ( $p$-value $=0.009, q$-value $=0.013$ ). We choose not to report related variables for brevity's sake in a table, but note that there were small and insignificant $5.2 \%$-point $(p$-value=0.124) and $3.5 \%$-point $(p$-value $=0.650)$ increases in the probability of reporting being able to borrow from a bank or friend, respectively. ${ }^{15}$ And there were no significant LEAP treatment difference in respondents reporting actually taking advantage of their self-reported increase in borrowing ability (variables include, took out loan last year $(0.1 \%$-points, $p$-value $=0.982)$, obtained loan $(-2.6 \%$ points, $p$-value $=0.636$ ) and ever took out a loan $(1.9 \%$-points, $p$-value $=0.721)$; all unreported in table). ${ }^{16}$

In sum, we infer that the program enjoyed clear success when it comes to increasing savings but some muted success in targeting the poor.

\footnotetext{
14 When the SHG borrowing ability variable in column 7 is included in the average effect calculation together with the savings variables in the final column of Table 8 , the average effect remains similar $0.544(\mathrm{p}$-value $=0.097)$ and the interaction term as well $-0.234(\mathrm{p}$-value $=0.129)$.

15 When all three borrowing ability-related variables (SHG, bank, friend) are included in the average effect calculation together with the savings variables of Table 8 , the average effect is 0.449 (p-value $=0.094$ ) and the interaction term is $-0.183(p$-value $=0.071$ ).

16 The average effect across these borrowing and loan indicators (ability to borrow from SHG, bank or friend, as well as took out loan last year, obtained loan and ever took out a loan) is 0.124 ( $p$-value $=0.080$ ) and the corresponding interaction term is $-0.152(p$-value $=0.124)$.
} 
Table 8

Savings.

(1)

Household currently Total current

has non zero savings household savings

(binary) (in 1000s riel)

(3)

$(4)$

Total current (5)

$\begin{array}{lll}\text { Total current } & \text { Total current } & \text { Inverse hyperbolic }\end{array}$

(in 1000s riel)

household savings

winsorized $(0.1 ; 0.9)$ riel$$
\text { riel) }
$$

savings (in 1000s

$$
\text { riel }
$$

Mean poor control
households

LEAP

Wild boot. p-value

Q-value

LEAP x Non-poor

household

Wild boot. p-value

Q-value

Non-poor household

Wild boot. p-value

Q-value

0.199
0.282
0.004
0.011
-0.177

0.17
0.427
0.048
0.489
0.492
540

24.901

14.901

30.037

0.082

0.082
-153.323

26.768

0.006

0.011

5.347

5.347
8.167

0.004

0.011
-87.799

0.842

1.246
0.005
0.011
-0.833

0.168
0.427
0.501
0.158
0.222
540

0.337

0.221
0.427

0.623
0.623

383.628

0.033

540

10.594

0.119

540

125.785

0.043

0.101
540

540

Note: Wild

o-file commune level (24), 10,000 replications. Q-values contro

* See discussions in footnotes 14 and 15 for average effects that include borrowing ability.

o-file by Michael L. Anderson, available at: http://are.berkeley.edu/ mlanderson/downloads/fdr_qvalues.do.zip. [Accessed May 25 2017].
* See discussions in footnotes 14 and 15 for average effects that include borrowing ability.

(6)

(6) (7)

Can house-hold

annual total

borrow from a SHC? production)

0.022

$\begin{array}{lll}0.041 & 0.232 & 0.547 \\ 0.019 & 0.009 & 0.095 \\ 0.023 & 0.013 & \\ -0.161 & -0.083 & -0.231\end{array}$

$\begin{array}{ll}0.244 & 0.400 \\ 0.427 & 0.467 \\ 0.201 & -0.04 \\ 0.022 & 0.492 \\ 0.101 & 0.492 \\ 537 & 540\end{array}$

0.102

0.467
-0.04
0.492
0.492

0.492

008) were calculated by row using the STATA 


\subsection{Livelihood and household expenditure outcomes}

Tables 9 through 11 report the estimated impact of LEAP on household production, assets and expenditures. The last summative column of Table 9 points to a positive, but small and insignificant average point estimate for production-related outcomes $(0.102, p$-value $=0.182)$. The average interaction term is close to zero and also insignificant $(0.020, p$-value $=0.850)$. These results imply no large net program impacts on production.

When considering individual indicators, livestock production in the form of meat and fish, as well as associated income increased substantially and statistically significantly among the poor in treated villages (columns 1 and 2 ). Both p- and qvalues are well below the 5\% threshold of significance. Magnitudes are economically important. Production increased by $93 \%$, which relative to the control group, amounts to 173,836 riels per capita (about 43 USD). There is a substantial and corresponding increase in sales income as well. These increases are consistent with our informal interviews with LEAP participants and program personnel who stated that participants frequently used LEAP funds to buy and raise chickens. They are also consistent with the claims of the program that 45 of the 52 producers' groups created by LEAP SHGs involved raising livestock (38 chicken-raising and 7 pig-raising groups). However, as we report in Tables 12 and 14 below, we could find no significant participation in producer groups in our sample, raising questions about how active these producer groups actually were.

These increases plausibly induced by LEAP were offset by a suggestively significant (significant p-values, but insignificant q-values) decreases in the annual income from crop sales per capita (column 3), and imprecisely estimated decreases in other annual revenue-generating activities per capita (see Appendix Table A2 for items included in these categories). Column 5 looks at the aggregate coefficient associated with LEAP when it comes to total production and similar to the last column displaying the average coefficient this exercise points to no production-enhancing effect of LEAP. Finally note that by and large the interaction terms (LEAP x Non-poor household) do not allow us to document any significant nor sizeable heterogeneity. Unreported in the table, the wild boot p-values associated with the effects on the non-poor (obtained by adding the respective leap coefficient and the interaction term) are $0.018,0.057,0.925,0.266$ and 0.955 for columns $1-5$. The corresponding $q$-values are $0.09,0.143,0.955,0.444$ and 0.955 . These patterns point to a robust positive effect on the non-poor for annual livestock production in column 1, and a suggestive positive effect (significant only using the p-value) in the case of annual income from livestock sales in column 2. These two effects echo at least qualitatively those found among the poor. This in contrast to column 3, which suggests reduced annual income from crop sales for the poor, but not at all for the rich households. In the case of the latter the point estimate is small and highly insignificant. Non-poor households may have shifted out of other revenue generating activities instead (compare column 4), yet the insignificant interaction and combined terms do not allow us to say this with confidence.

Table 10 presents results with respect to asset stocks. They indicate that LEAP villages did not hold statistically larger stocks of assets than control villages. The average coefficient is tiny and insignificant $(0.026, p$-value $=0.773)$; there are no power issues. Individual point estimates are also small and insignificant. While Table 9 showed that LEAP villages experienced greater livestock production, this greater production did not lead to significantly greater holdings of livestock. A few remarks are in order: First, this could be because LEAP livestock growers raised chickens and pigs which reach maturity and are sold for slaughter in eight to twelve weeks and six months, respectively, an interpretation that is consistent with the statistically significant increase in income from livestock. The null effect on livestock holdings could be due to the difference between a stock and a flow. Second, the model concerning livestock acquired (i.e. livestock flows) is expressed in individual animals (e.g. chicks or piglets for raising). The histogram in Fig. A1 (see online appendix) suggests differences between treated and control communities in this count variable. Treated communities had slightly fewer households with no livestock acquisitions and generally slightly more households in treated communities acquired livestock at each level with one major exception: control communities had two households that were extreme outliers, acquiring more than thirty animals. When those two outliers are excluded the point estimate on the treatment effect doubles to 0.32 but it is still statistically insignificant at conventional levels. In total these results point to slightly greater acquisition of livestock in treated communities but those few households that did switch into livestock production earned more production income for doing so. Overall, our data may not be detailed enough to pinpoint these relative dynamics and apparent heterogeneity.

Increases in savings should require reduced expenditures in the short run. The second column of Table 11 indicates suggestively that households in LEAP communities reduced miscellaneous expenditures, but the estimate related to expenditures was in general not statistically significant and the standardized mean estimate in the last column is substantively very small and statistically insignificant $(-0.017, p$-value $=0.880)$. While some reductions in expenditures must have been necessary for SHG members to increase savings, LEAP does not appear to have required large impacts on expenditures overall. Finally, note that the average estimate associated with the interaction term of treatment with the non-poor indicator is negative, insignificant and small $(-0.107, p$-value $=0.505)$.

\subsection{Social capital outcomes}

We now turn to the influence of the program on social capital as measured by economic networks (Table 12), social networks (Table 13) and group memberships other than SHGs (Table 14). One thing to note here is that we did not record when links were formed or groups were joined, so the following results provide a temporal snapshot only. Consider Table 12 
Table 9

Production.

\begin{tabular}{|c|c|c|c|c|c|c|}
\hline $\begin{array}{l}\text { All dep. variables inverse hyperbolic } \\
\text { sine transf. }\end{array}$ & $\begin{array}{l}(1) \\
\text { Annual livestock } \\
\text { production per } \\
\text { capita, last one year } \\
\text { (in 1000s riel) }\end{array}$ & $\begin{array}{l}\text { (2) } \\
\text { Annual income from } \\
\text { livestock sales per } \\
\text { capita, last one year } \\
\text { (in 1000s riel) }\end{array}$ & $\begin{array}{l}\text { (3) } \\
\text { Annual income from } \\
\text { crop sales per capita, } \\
2012 \text { harvest season } \\
\text { (in 1000s riel) }\end{array}$ & $\begin{array}{l}(4) \\
\text { Other annual } \\
\text { revenue-generating } \\
\text { activities per capita, } \\
2012 \text { (in 1000s riel) }\end{array}$ & $\begin{array}{l}\text { (5) } \\
\text { Annual total } \\
\text { production (in } 1000 \mathrm{~s} \\
\text { riel) }\end{array}$ & $\begin{array}{l}\text { (6) } \\
\text { Avg. effect }\end{array}$ \\
\hline Mean poor control households (levels) & 187.121 & 105.624 & 113.25 & 1387.08 & 1793.074 & \\
\hline LEAP & 0.657 & 1.120 & -0.577 & -0.097 & 0.028 & 0.102 \\
\hline Wild boot. p-value & 0.006 & 0.002 & 0.097 & 0.698 & 0.860 & 0.185 \\
\hline Q-value & 0.015 & 0.010 & 0.162 & 0.860 & 0.860 & \\
\hline LEAP x Non-poor household & 0.331 & 0.111 & 0.513 & -0.511 & -0.039 & 0.020 \\
\hline Wild boot. p-value & 0.382 & 0.828 & 0.530 & 0.291 & 0.861 & 0.850 \\
\hline Q-value & 0.861 & 0.861 & 0.861 & 0.861 & 0.861 & \\
\hline Non-poor household & -0.019 & 0.315 & 0.797 & 0.304 & 0.300 & \\
\hline Wild boot. p-value & 0.941 & 0.392 & 0.024 & 0.215 & 0.091 & \\
\hline Q-value & 0.941 & 0.490 & 0.120 & 0.359 & 0.228 & \\
\hline $\mathrm{N}$ & 540 & 540 & 540 & 540 & 540 & \\
\hline
\end{tabular}

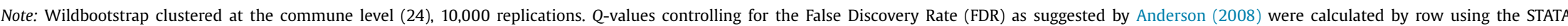
do-file by Michael L. Anderson, available at: http://are.berkeley.edu/ mlanderson/downloads/fdr_qvalues.do.zip. [Accessed May 25 2017]. 


\begin{tabular}{|c|c|c|c|c|}
\hline & $\begin{array}{l}\text { (1) } \\
\text { Assets per capita, in } \\
\text { 1000s riel -inverse } \\
\text { hyperbolic sine transf. }\end{array}$ & $\begin{array}{l}\text { (2) } \\
\text { Livestock holdings per capita, } \\
\text { current, in 1000s riel - } \\
\text { inverse hyperbolic sine transf. }\end{array}$ & $\begin{array}{l}\text { (3) } \\
\text { Livestock acquired (total } \\
\text { number), over last one year }\end{array}$ & $\begin{array}{l}\text { (4) } \\
\text { Avg. effect }\end{array}$ \\
\hline $\begin{array}{l}\text { Mean poor control } \\
\text { households (levels) }\end{array}$ & 276.949 & 241.315 & 0.950 & \\
\hline LEAP & 0.025 & 0.030 & 0.161 & 0.026 \\
\hline Wild boot. p-value & 0.925 & 0.955 & 0.675 & 0.773 \\
\hline Q-value & 0.955 & 0.955 & 0.955 & \\
\hline LEAP x Non-poor household & -0.234 & 0.509 & -0.105 & 0.015 \\
\hline Wild boot. p-value & 0.362 & 0.464 & 0.866 & 0.909 \\
\hline Q-value & 0.696 & 0.696 & 0.866 & \\
\hline Non-poor household & 1.448 & 0.896 & -0.040 & \\
\hline Wild boot. p-value & 0.000 & 0.020 & 0.946 & \\
\hline Q-value & 0.001 & 0.030 & 0.946 & \\
\hline $\mathrm{N}$ & 540 & 540 & 540 & \\
\hline
\end{tabular}

Note: Wildbootstrap clustered at the commune level (24), 10,000 replications. Q-values controlling for the False Discovery Rate (FDR) as suggested by Anderson (2008) were calculated by row using the STATA do-file by Michael L. Anderson, available at: http://are.berkeley.edu/ mlanderson/downloads/ fdr_qvalues.do.zip. [Accessed May 25 2017].

Table 11

Expenditures.

\begin{tabular}{llll}
\hline $\begin{array}{l}\text { All dep. variables inverse } \\
\text { hyperbolic sine transf. }\end{array}$ & $\begin{array}{l}(1) \\
\text { Non-food expenditures per } \\
\text { capita, past 30 days (in 1000s } \\
\text { riel) }\end{array}$ & $\begin{array}{l}(2) \\
\text { Misc. expenditures per } \\
\text { capita, past 12 months (in } \\
1000 \text { s riel) }\end{array}$ & $\begin{array}{l}\text { (3) } \\
\text { Bought food consumption per } \\
\text { capita, past 7 days (in 100s s } \\
\text { riel) }\end{array}$ \\
\hline Mean poor control & 25.700 & 350.094 & 144.400 \\
households (levels) & & & \\
LEAP & 0.105 & -0.172 & 0.008 \\
Wild boot. p-value & 0.262 & 0.161 & 0.956 \\
Q-value & 0.393 & 0.393 & 0.956 \\
LEAP x Non-poor household & -0.118 & -0.013 & -0.118 \\
Wild boot. p-value & 0.327 & 0.948 & 0.526 \\
Q-value & 0.789 & 0.948 & 0.789 \\
Non-poor household & 0.174 & 0.629 & 0.183 \\
Wild boot. p-value & 0.023 & 0.000 & 0.086 \\
Q-value & 0.035 & 0.001 & 0.086 \\
N & 540 & 540 & 540
\end{tabular}

Note: Wildbootstrap clustered at the commune level (24), 10,000 replications. Q-values controlling for the False Discovery Rate (FDR) as suggested by Anderson (2008) were calculated by row using the STATA do-file by Michael L. Anderson, available at: http://are.berkeley.edu/ mlanderson/downloads/ fdr_qvalues.do.zip. [Accessed May 25 2017].

where we present results for six types of economic relationships: funeral group, ${ }^{17}$ "exchanging hands," ${ }^{18}$ buying or selling, as well as employee, co-worker and producer group ones. The average estimate associated with these economic networks is insignificant (We did not include producer group links in this average effect calculation due to zero links and thus a zero standard deviation in the control.). The point estimate of 0.360 standard deviations falls in to the small-medium range according to Cohen's D with a $p$-value of 0.16 . So, we may be lacking power here. The average interaction term of LEAP and poverty status is very small and insignificant $(-0.047, p$-value $=0.501)$. These patterns warrant a closer look at the individual point estimate sets. Estimates are positive and large relative to the mean in the poor control group when it comes to the funeral group and exchange of hands-related network links. For instance, the impact on the likelihood of reporting at least one funeral group link is 17.7\%-points compared to an average prevalence of $2.3 \%$ in control areas (column 1). However, this relatively large difference may be misleading given the low number of such links in the first place and their concentration in few villages: 17 (14) of the 18 control (treated) villages have no funeral group links at all. Column 2 shows that LEAP close to doubles the number of network links due to the exchange of hands but we suffer from power problems $(p$-value $=0.153$, $q$-value $=0.765)$. The estimate for buying and selling links is positive, modest relative to the control mean (12\%) and highly insignificant ( $p$-value $=0.772, q$-value $=0.924)$. The next two columns indicate negative but very small and highly insignificant estimates $(-4.2 \% ;-7.9 \%)$ for work-related network links. The point estimate for producer networks in column 6 is positive as

\footnotetext{
${ }^{17}$ These are risk-sharing groups in which members agree to cover the cost for funerals of other members. This is a relatively rare link in our sample so we use a binarized version of that takes on one for having at least one link to another experimental session participant and zero otherwise.

${ }^{18}$ This a direct translation of the Khmer expression for voluntary labor exchange in which one farmer works on another farmer's land in exchange for an explicit agreement that the second farmer will work on the first farmer's land at a later date. This is as much a favor exchange relationship as an economic one. Although given the importance of agriculture to the region, we include it here as a fundamental economic relationship.
} 
Table 12

Economic Networks.

\begin{tabular}{|c|c|c|c|c|c|c|c|}
\hline $\begin{array}{l}\text { Links to other experimental } \\
\text { participants }\end{array}$ & $\begin{array}{l}\text { (1) } \\
\text { Funeral group ( } 1=\text { having } \\
\text { at least one link, } 0 \\
\text { otherwise) }\end{array}$ & $\begin{array}{l}\text { (2) } \\
\text { Exchange hands (for free, } \\
\text { nr. of links) }\end{array}$ & $\begin{array}{l}\text { (3) } \\
\text { Regular buying and } \\
\text { selling link (undirected, } \\
\text { nr. of links) }\end{array}$ & $\begin{array}{l}\text { (4) } \\
\text { Employee-relationship } \\
\text { (undirected, nr. of links) }\end{array}$ & $\begin{array}{l}\text { (5) } \\
\text { Coworker (nr. of links) }\end{array}$ & $\begin{array}{l}(6) \\
\text { Producer group } \\
\text { (1=having at least one } \\
\text { link, } 0 \text { otherwise })\end{array}$ & $\begin{array}{l}\text { (7) } \\
\text { Avg. effect } \\
\text { (cols. 1-5)* }\end{array}$ \\
\hline Mean poor control households & 0.023 & 2.364 & 3.058 & 1.480 & 2.671 & 0 & \\
\hline LEAP & 0.177 & 2.199 & 0.372 & -0.062 & -0.210 & 0.048 & 0.36 \\
\hline Wild boot. p-value & 0.330 & 0.153 & 0.772 & 0.924 & 0.837 & 0.452 & 0.16 \\
\hline Q-value & 0.904 & 0.904 & 0.924 & 0.924 & 0.924 & 0.904 & \\
\hline LEAP x Non-poor household & -0.019 & -0.270 & -0.091 & -0.039 & -0.026 & -0.014 & -0.047 \\
\hline Wild boot. p-value & 0.697 & 0.499 & 0.874 & 0.915 & 0.935 & 0.434 & 0.501 \\
\hline Q-value & 0.935 & 0.935 & 0.935 & 0.935 & 0.935 & 0.935 & \\
\hline Non-poor household & 0.000 & 0.365 & 0.013 & 0.485 & -0.094 & 0.000 & \\
\hline Wild boot. p-value & 0.536 & 0.177 & 0.976 & 0.153 & 0.734 & 0.970 & \\
\hline Q-value & 0.976 & 0.531 & 0.976 & 0.531 & 0.976 & 0.976 & \\
\hline $\mathrm{N}$ & 511 & 511 & 511 & 511 & 511 & 511 & \\
\hline
\end{tabular}

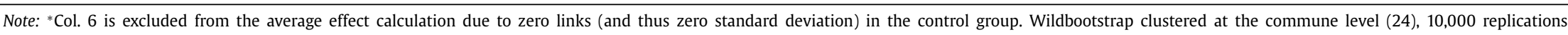

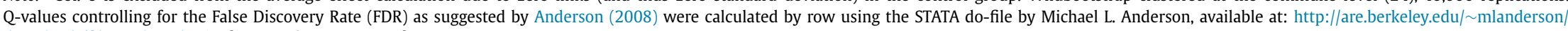
downloads/fdr_qvalues.do.zip. [Accessed May 25 2017]. 
Table 13

Social Networks.

\begin{tabular}{|c|c|c|c|c|c|c|c|}
\hline $\begin{array}{l}\mathrm{Nr} \text { of links to other } \\
\quad \text { experimental participants }\end{array}$ & $\begin{array}{l}\text { (1) } \\
\text { Worship group }\end{array}$ & $\begin{array}{l}(2) \\
\text { Babysitting }\end{array}$ & $\begin{array}{l}(3) \\
\text { Seek advice }\end{array}$ & $\begin{array}{l}\text { (4) } \\
\text { Social Group }\end{array}$ & $\begin{array}{l}(5) \\
\text { Volunteering }\end{array}$ & $\begin{array}{l}(6) \\
\text { Borrow (non } \\
\text { monetary) }\end{array}$ & $\begin{array}{l}\text { (7) } \\
\text { Avg. effect }\end{array}$ \\
\hline Mean poor control households & 1.439 & 0.353 & 0.711 & 2.578 & 1.838 & 1.364 & \\
\hline LEAP & 1.494 & 0.066 & 0.338 & 1.052 & 0.477 & 0.660 & 0.256 \\
\hline Wild boot. p-value & 0.318 & 0.712 & 0.344 & 0.529 & 0.641 & 0.575 & 0.205 \\
\hline Q-value & 0.712 & 0.712 & 0.712 & 0.712 & 0.712 & 0.712 & \\
\hline LEAP x Non-poor household & -0.340 & -0.161 & 0.032 & -0.243 & -0.687 & -0.104 & -0.091 \\
\hline Wild boot. p-value & 0.466 & 0.456 & 0.865 & 0.626 & 0.025 & 0.718 & 0.233 \\
\hline Q-value & 0.862 & 0.862 & 0.865 & 0.862 & 0.150 & 0.862 & \\
\hline Non-poor household & 0.055 & 0.106 & 0.113 & 0.363 & 0.644 & -0.023 & \\
\hline Wild boot. p-value & 0.698 & 0.214 & 0.248 & 0.207 & 0.002 & 0.883 & \\
\hline Q-value & 0.838 & 0.372 & 0.372 & 0.372 & 0.012 & 0.883 & \\
\hline $\mathrm{N}$ & 511 & 511 & 511 & 511 & 511 & 511 & \\
\hline
\end{tabular}

Note: Wildbootstrap clustered at the commune level (24), 10,000 replications. Q-values controlling for the False Discovery Rate (FDR) as suggested by Anderson(2008) were calculated by row using the STATA do-file by Michael L. Anderson, available at: http://are.berkeley.edu/ mlanderson/downloads/ fdr_qvalues.do.zip. [Accessed May 25 2017].

Table 14

Group Memberships.

\begin{tabular}{|c|c|c|c|c|c|c|c|}
\hline Memberships of household in associations (binary) & $\begin{array}{l}(1) \\
\text { Producer }\end{array}$ & $\begin{array}{l}(2) \\
\text { Rice seed }\end{array}$ & $\begin{array}{l}\text { (3) } \\
\text { Funeral }\end{array}$ & $\begin{array}{l}\text { (4) } \\
\text { Youth }\end{array}$ & $\begin{array}{l}(5) \\
\text { Irrigation }\end{array}$ & $\begin{array}{l}(6) \\
\text { Women }\end{array}$ & $\begin{array}{l}\text { (7) } \\
\text { Avg. effect }\end{array}$ \\
\hline Mean poor control households & 0.039 & 0.210 & 0.110 & 0.033 & 0.017 & 0.199 & \\
\hline LEAP & 0.034 & 0.293 & -0.055 & 0.017 & 0.017 & 0.125 & 0.210 \\
\hline Wild boot. p-value & 0.238 & 0.001 & 0.282 & 0.494 & 0.425 & 0.421 & 0.066 \\
\hline Q-value & 0.494 & 0.006 & 0.494 & 0.494 & 0.494 & 0.494 & \\
\hline LEAP x Non-poor household & -0.012 & -0.110 & -0.025 & 0.048 & 0.048 & -0.008 & 0.028 \\
\hline Wild boot. p-value & 0.730 & 0.285 & 0.531 & 0.227 & 0.117 & 0.914 & 0.854 \\
\hline Q-value & 0.876 & 0.570 & 0.797 & 0.570 & 0.570 & 0.914 & \\
\hline Non-poor household & -0.027 & -0.008 & 0.024 & -0.011 & 0.006 & -0.008 & \\
\hline Wild boot. p-value & 0.157 & 0.914 & 0.461 & 0.643 & 0.628 & 0.811 & \\
\hline Q-value & 0.914 & 0.914 & 0.914 & 0.914 & 0.914 & 0.914 & \\
\hline $\mathrm{N}$ & 540 & 540 & 540 & 540 & 540 & 540 & \\
\hline
\end{tabular}

Note: Wildbootstrap clustered at the commune level (24), 10,000 replications. Q-values controlling for the False Discovery Rate (FDR) as suggested by Anderson(2008) were calculated by row using the STATA do-file by Michael L. Anderson, available at: http://are.berkeley.edu/ mlanderson/downloads/ fdr_qvalues.do.zip. [Accessed May 25 2017].

expected (4.8\%-points) but insignificant. This is disappointing given the purported creation of producer groups as indicated by the official LEAP report. In our data the producer network was very sparse and not well distributed. In control communes nobody reported producer group links. ${ }^{19}$ In LEAP communes 0.348 links were reported on average (with a median of zero). That said only $4.8 \%$ of the sample or 13 subjects report at least one link. All of these non-zero links are due in just two villages. These findings raise questions about how real and certainly how active the LEAP-created producer groups were. The overall conclusion from Table 12 is that LEAP had no broad nor robust effects on economic networks other than those directly linked to SHGs (recall column 2, Table 7). However, we cannot statistically rule out small to medium average effects and meaningful effects on some sub-indicators (in column 1 and 2).

Table 13 reports estimates for the number of links to others via social activities and associations: Worship, Babysitting, Advice-seeking, Social Groups, Volunteering and Borrowing (non-monetary). We document a positive but insignificant average estimate that is just above the "small" cutoff based on Cohen's D (0.256 standard deviations, $p$-value $=0.205)$. The average interaction term associated with the non-poor status is merely suggestive of a reduced positive effect among the non-poor $(-0.091, p$-value $=0.205)$. Across the board, the individual estimates associated with LEAP are positive and sizable and unfortunately imprecisely estimated. We acknowledge power issues.

Table 14 displays LEAP's influence on group membership (other than SHG and savings groups). These data, from the household survey, are self-reported and thus different to the aforementioned network measures. The average estimate points to some modest overall increases in such memberships induced by LEAP $(0.210, p$-value $=0.066)$. The effect on the poor and non-poor is qualitatively similar as indicated by a small interaction term $(0.028, p$-value $=0.854)$. Interesting patterns emerge when dissecting this average estimate. Self-reported membership in producers' groups, shown in column 1, was statistically no different in program and control communities, which is disappointing given the program's putative creation of 52 producer groups. The small absolute coefficient on the treatment dummy $(0.034)$ does represent a doubling of producer

\footnotetext{
${ }^{19}$ As the mean in the control group was zero, we did not include the producer network effect in the average effect calculation in the final column of Table 2; one cannot divide the effect by a standard deviation of zero.
} 


\begin{tabular}{|c|c|c|c|c|c|}
\hline & \multirow{2}{*}{$\begin{array}{l}\text { (1) } \\
\text { Number of community meetings } \\
\text { attended over the last year }\end{array}$} & \multicolumn{3}{|c|}{$\begin{array}{l}(2) \\
\text { Household member helped, past } 6 \text { months (all binary): }\end{array}$} & \multirow[t]{2}{*}{$\begin{array}{l}\text { (5) } \\
\text { Avg. effect }\end{array}$} \\
\hline & & $\begin{array}{l}\text { Build or } \\
\text { rebuild school }\end{array}$ & $\begin{array}{l}\text { Build or repair } \\
\text { road }\end{array}$ & $\begin{array}{l}\text { Clean up public } \\
\text { space in the } \\
\text { community }\end{array}$ & \\
\hline Mean poor control households & 6.221 & 0.343 & 0.580 & 0.215 & \\
\hline LEAP & 1.511 & 0.037 & 0.018 & 0.058 & 0.143 \\
\hline Wild boot. p-value & 0.088 & 0.779 & 0.880 & 0.514 & 0.337 \\
\hline Q-value & 0.352 & 0.880 & 0.880 & 0.880 & \\
\hline LEAP $x$ Non-poor household & 0.859 & -0.134 & -0.042 & -0.053 & -0.076 \\
\hline Wild boot. p-value & 0.520 & 0.026 & 0.524 & 0.524 & 0.355 \\
\hline Q-value & 0.524 & 0.104 & 0.524 & 0.524 & \\
\hline Non-poor household & 0.464 & 0.051 & 0.049 & 0.065 & \\
\hline Wild boot. p-value & 0.329 & 0.137 & 0.350 & 0.311 & \\
\hline Q-value & 0.350 & 0.350 & 0.350 & 0.350 & \\
\hline $\mathrm{N}$ & 540 & 540 & 540 & 540 & \\
\hline
\end{tabular}

Note: Wildbootstrap clustered at the commune level (24), 10,000 replications. Q-values controlling for the False Discovery Rate (FDR) as suggested by Anderson(2008) were calculated by row using the STATA do-file by Michael L. Anderson, available at: http://are.berkeley.edu/ mlanderson/downloads/ fdr_qvalues.do.zip. [Accessed May 25 2017].

group membership compared to the low control group mean (0.039), but it is not statistically significant $(p$-value $=0.238$, $q$-value $=0.494$ ) and one would expect a larger effect given the program's claim that almost half the SHGs created livestock groups.

LEAP more than doubled membership in rice seed groups ( $p$-value $=0.001, q$-value $=0.006$ ), which are common across villages. Rice seed groups were not created by the LEAP program so LEAP appears to have caused follow-on increases in membership in new or existing ones. To examine the broader relationship between rice seed and SHG groups, we regressed rice seed membership on a SHG dummy controlling for poverty status and village fixed effects (absorbing the LEAP treatment). SHG membership is correlated with a 71\%-point increase in rice seed membership $(p$-value $=0.000)$ even controlling for LEAP treatment, pointing to complementarity of these groups. This suggests that Cambodian villagers that save via SHGs also are more likely to "save" in rice-seed banks. Thus, LEAP suggestively correlates with increased membership in rice-seed groups because it increases the numbers of SHGs. We did not expect this result and so, unfortunately, we cannot comment on it further with any confidence. Perhaps in rural Cambodia, where savings institutions are very weak, these are the only two common savings institutions available to villagers. If so, it could be that those who are prone to save, make use of both of them.

Further, the effect on funeral group membership was negative, which is at odds with the positive but insignificant effect we found on the likelihood knowing somebody from a funeral group. The correlation between funeral group membership and the number of links to funeral group members is negative and small both in treated $(-0.072)$ and control $(-0.048)$ villages. Funeral group membership is quite rare and skewed (11.9\% in control and $5.6 \%$ in treated villages), which may explain these results. Column 4 and 5 point to no significant and sizeable absolute effects on youth and irrigation groups, which are not very present in the control group.

Column 6 suggests a 63\% increase in women's group participation. However, the coefficient is insignificant ( $p$ value $=0.421, q$-value $=0.494$ ) and the test is underpowered. SHGs were newly created and while men were not excluded by the program, the local context and nature of the program led to mainly female members. This is reflected in who participated in our behavioral activities as well. The overwhelming majority was female. In control villages the correlation between women's groups and SHG is -0.015 and in treated villages the correlation is 0.04 . In other words, there is a weak correlational link.

We were not only interested in testing for LEAP's effects on networks and group formation, but also on self-reported pro-social actions. Table 15 tells us that LEAP had an insignificant and less than small influence on a host of community action indicators (see last column, average effect $=0.143, p$-value $=0.337$ ). The estimate is (suggestively) reduced among the non-poor (average effect $=-0.076, p$-value $=0.355$ ). It is worth noting that households in program areas attended 1.511 more meetings, a $24 \%$ increase over the average number of attended meetings of 6.221 by poor control households. The point estimate is significant at the $10 \%$ level when taking its p-value, but the positive finding does not pass adjustment for multiple hypothesis testing ( $q$-value $=0.352$ ); low power may be an issue. The remaining columns $(2-4)$ cannot document significant estimates of LEAP for helping to build or rebuild a school or road nor cleaning up a public space in the last 6 months, so we conclude that LEAP had no wider and economically important effect on community actions.

Table 16 reports the impacts of the program on laboratory measures of social norms. The final column reports the average estimate across measures: 0.12 standard deviations and insignificant ( $p$-value $=0.242$ ). While positive as hoped for by LEAP, the average estimate is very modest (well below Cohen's D of 0.2 for small effect size). It is suggestively smaller among the non-poor but the interaction is highly insignificant (by $-0.048, p$-value $=0.719$ ). 


\begin{tabular}{|c|c|c|c|c|c|}
\hline & $\begin{array}{l}(1) \\
\text { Altruism (amount sent } \\
\text { in dictator game, } \\
0-3000 \text { riel) }\end{array}$ & $\begin{array}{l}(2) \\
\text { Public good } \\
\text { contribution (yes=1, } \\
\text { no=0) }\end{array}$ & $\begin{array}{l}\text { (3) } \\
\text { Trust (amount sent in } \\
\text { the trust game, } \\
0-3000 \text { riel) }\end{array}$ & $\begin{array}{l}\text { (4) } \\
\text { Trustworthiness } \\
\text { (fraction returned in } \\
\text { the trust game) }\end{array}$ & Avg. effect \\
\hline $\begin{array}{l}\text { Mean poor control } \\
\text { households }\end{array}$ & 684.971 & 0.642 & 493.827 & 0.154 & \\
\hline LEAP & 99.877 & 0.043 & 116.562 & -0.001 & 0.120 \\
\hline Wild boot. p-value & 0.089 & 0.505 & 0.297 & 0.96 & 0.242 \\
\hline Q-value & 0.356 & 0.674 & 0.594 & 0.96 & \\
\hline LEAP x Non-poor household & -99.744 & -0.005 & -135.112 & 0.024 & -0.048 \\
\hline Wild boot. p-value & 0.479 & 0.949 & 0.393 & 0.497 & 0.719 \\
\hline Q-value & 0.663 & 0.949 & 0.663 & 0.663 & \\
\hline Non-poor household & 144.441 & 0.025 & 303.792 & -0.01 & \\
\hline Wild boot. p-value & 0.083 & 0.680 & 0.022 & 0.715 & \\
\hline Q-value & 0.166 & 0.715 & 0.088 & 0.715 & \\
\hline $\mathrm{N}$ & 511 & 510 & 243 & 266 & \\
\hline
\end{tabular}

Note: Wildbootstrap clustered at the commune level (24), 10,000 replications. Q-values controlling for the False Discovery Rate (FDR) as suggested by Anderson(2008) were calculated by row using the STATA do-file by Michael L. Anderson, available at: http://are.berkeley.edu/ mlanderson/downloads/ fdr_qvalues.do.zip. [Accessed May 25 2017].

Turning to the results on individual indicators, column 1 presents estimates for our measure of altruism to wit the amount donated by the subject to the needy family. LEAP increased donations among the treated poor by 99.9 riels. In comparison, poor subjects from control communities donated about 685 riels, a little less than one-fourth of the endowment. The treatment effect amounts to a 15\% increase. While the effect is individually significant at the $10 \%$ level $(p$-value $=0.089)$, it does not survive adjusting for multiple hypothesis testing ( $q$-value=0.356). Interestingly, the interaction effect associated with the non-poor is the opposite sign and the same magnitude but imprecisely estimated. Column 2 presents linear probability estimates of the effect of LEAP on contributions in the dichotomous public good activity. Around 64\% of subjects contributed to the public good in poor control households. There is no significant difference between subjects from treated and control communities, either in the full sample or in sub-categories of poverty. Contributions in the LEAP villages were 4.3\%-points (or 7\%) higher than in control villages, but this modest increment was not statistically significant. The interaction term with the poverty indicator is tiny and highly significant $(-0.005, p$-value $=0.949)$.

Column 3 shows results for trust-the amount sent by the "investor" in the activity. Column 4 shows the ones for trustworthiness-the amount returned by the trustee as a percentage of the total amount available to the trustee. Recall, the total amount available to the trustee is their initial endowment of 3000 riels plus triple the amount the investor gave them. The number of investors and trustees is unequal because, when there was an odd number of subjects in the lab session, we randomly matched two trustees to one investor. In those cases, the trustees received the payoff consistent with their actions and the relevant investors received the payoff decided by the first trustee with whom they were randomly paired. Focusing first on column 3, poor subjects did send more in the treated villages than those residing in control villages, but the difference is not statistically significant ( 116.6 riels, $p$-value $=0.297, q$-value $=0.594$ ). There may be a problem with a low-powered test since this equates to a meaningful $24 \%$ mean increase. Similar to behavior in the dictator game, we find that the treated non-poor's behavior suggestively offsets the positive treatment effect $(-135.112, p$-value $=0.393)$. Turning to the effects of the program on trustworthiness in column 4 , the program did not produce significant increases in trustworthy behavior. In this case there is little concern over a low-powered test, because the estimated treatment effect is tiny ( $-0.1 \%$-points relative to a control mean of $15.4 \%, p$-value $/ q$-value $=0.96)$. Likewise, the interaction term is small and insignificant $(2.4 \%$-points, $p$-value $=0.497, q$-value $=0.663)$.

\subsection{Social capital outcomes - robustness and mechanisms}

We now present a series of robustness and/or mechanisms checks relating to the behavioral patterns:

First, LEAP did not impact risk and time preferences (see Table A3 in the online appendix). The average effect (0.070, $p$-value $=0.409)$ and both individual effects are very small relative to the control mean $(4.6 \%, 2.9 \%)$ in magnitude and highly insignificant, so we can exclude the influence of these deeper mechanisms/cofounders.

Second, while we pass most randomization balancing tests, the number of family links is imbalanced (see Table 3). This may have influenced laboratory behavior. If treated participants were more familiar with other session members, this may have spuriously increased pro-social behavior. Table A4 in the online appendix controls for the total number of family links in the game session. On the one hand note that the number of family links is positively correlated with pro-social behavior, however the relationship tends to be statistically weak. We can only report a significant and positive correlation between trustworthiness and family links (see column 4). On the other hand, we find that controlling for family links tends to lower the positive coefficients associated with the LEAP treatment indicator, which is reflected in a lower average effect (falling from 0.120 to 0.075 ; compare last columns of Tables 16 and A4). This is suggestive of a spurious correlation of LEAP and 
pro-social behavior operating via family links. Notably, when it comes to altruism, the coefficient falls by $11 \%$, but is slightly more precisely estimated. Overall, the effect of LEAP on altruism remains relatively modest relative to the mean (13\%). In sum, controlling for family links has some but no substantive implication for the interpretation of our results.

Third, there may be a concern that winnings earlier in the experimental sessions are correlated with subsequent behavior. In Table A5 (see online appendix) we regress pro-social behavior in the control group (to abstract from treatment effects) on prior winnings in the lottery activity. There is no evidence of a significant link.

Fourth, LEAP had little effect on economic and social networks (other than SHGs), which may explain the small and insignificant positive effects on pro-social behavior. That said, LEAP has changed select economic variables such as savings, which may subsequently boost pro-social behavior. One theoretical explanation may relate to social preferences that feature inequity aversion (both with respect to own and other's inequitable economic outcomes, see Fehr and Schmidt, 1999). In particular, the willingness to help a poor and unknown family in the community may be influenced by one's own economic situation. This economic mechanism could explain the positive albeit small and imprecise effects we saw in Table 16 . ${ }^{20}$ To examine this further, we regressed pro-social behavior (in the dictator, trust and public good games) on total annual production and savings. In that regression, we also include the number of network links to SHG members in line with socialcapital-creating mechanism modeled by Avdeenko and Gilligan (2015). We perform this exploratory and correlational analysis in the sample of control households to avoid treatment-related endogeneity concerns. Table A6 (see online appendix) documents a positive and significant correlation between altruism and household production, as well as a positive and significant correlation between savings and the likelihood of public good contribution. Relatedly, savings were induced via group activities, which could link to the public good game behavior or the willingness to contribute to a group/community. Individual economic outcomes in turn may influence altruism. While the boost to savings was significant, the very small and highly insignificant increase in total household production due to LEAP may have been too small to bring about larger and noticeable pro-social behavioral change. The same table also points to no significant and if at all negative correlation between the number of SHG links and pro-social behavior. One caveat here is that of course the nature of such SHG links may differ between control and treated areas. In sum, these "control group" patterns are suggestively in line with a plausible theory of change running from improved economic conditions to pro-social behavior.

\section{Conclusion}

We reported the results of a randomized field trial of the Livelihood Enhancement and Associations among the Poor (LEAP) program, which was designed to improve livelihoods, encourage savings and civic participation and create social capital among the poorest residents of Siem Reap province by organizing self-help groups. The program enjoyed partial successes in its goals, in particular, substantially increasing the number of households that had some savings. The program also dramatically increased the poor's membership in self-help groups and led to shifts in the poor's livelihoods towards meat production and income derived from it. In net, livelihoods were not enhanced significantly however. Average effects on civic engagement and social capital were positive but small and insignificant. We acknowledge low-powered tests here.

These promising results emerged from a small sample of only 540 households after only eighteen months of a pilot program rather than the three-year intervention that was originally planned. With respect to the small sample our aim in this paper was to transparently acknowledge under-powered estimates whenever pertinent. In the same vein, we also acknowledge the commonly ignored fact that significant results in a small sample may be overestimates (Button et al., 2013). Our design also suffered from some flaws (few and imbalanced treated units), that may lead to $p$-values that are too small (MacKinnon and Webb, 2017a,b, 2018). Yet given the still limited evidence stemming from RCTs in this area, and our comprehensive measurement strategy, we are confident that our study adds new insights to the literature.

This study also points to avenue for future research. First, the program we study was short and its implementation was interrupted due to the moratorium on World Bank funding to Cambodia. Given the promising findings in this study even under those adverse conditions, it would be worthwhile to evaluate the program as it was meant to be implemented. The large impact we find on the number of people who had some savings and the significant but perhaps smaller impacts on absolute amounts of savings could indicate that savings may have been higher while the program was running at full force (before the World Bank funding hiatus). Given more time, the increased association among the poor in SHGs may produce even stronger community-wide improvements. A second avenue of study concerns the intensity of the social links that the program created. We show that SHG membership and related networks links have increased. Unfortunately, due to our respondents' time and recall constraints we could not collect data on how active or intense this participation in the groups was during and after the end of the program. Doing so may be an interesting topic for future research.

In summary, while further study is always prudent before drawing firm conclusions, the results of this evaluation relating to SHG group creation and savings are sufficiently encouraging to recommend that LEAP-like programs be further instituted and investigated.

\section{Declaration of Competing Interest}

\section{None.}

\footnotetext{
${ }^{20}$ We are grateful to an anonymous referee for suggesting this exploratory investigation ex-post.
} 


\section{Acknowledgements}

We thank two anonymous reviewers and the editor Laura Schechter for detailed and most helpful comments. This research collaboration was initiated by Development Impact Evaluation's (DIME's) IE in Fragile States program and received funding from the Knowledge for Change Program (KCP). The authors would like to thank Marcus Holmlund (World Bank) for his role in client engagement, data collection, and securing funding for the study. We are grateful to Younell Hay, Top Neth and Mok Tonh of the LEAP team and to Mudita Chamroeun, World Bank LEAP task team leader, for supporting this impact evaluation. We would like to thank Ramji Dhakal, Ly Vouchlong, Pong Pheakdey Boramy, Chea Bunnary, Hang Chansophea, Soklang Kheang, Va Wisal, and SBK Research and Development for collecting the data used in this study. We have received helpful comments in seminars at ETH Zurich, Wageningen University and DIW Berlin.

\section{Funding}

World Bank's Development Impact Evaluation's (DIME's) IE in Fragile States program through the Knowledge for Change Program (KCP). Role of the funding source is described in the text.

\section{Supplementary materials}

Supplementary material associated with this article can be found, in the online version, at doi:10.1016/j.jebo.2020.09.029.

\section{References}

Anderson, M., 2008. Multiple inference and gender differences in the effects of early intervention: a reevaluation of the abecedarian, perry preschool, and early training projects. J. Am. Stat. Assoc. 103 (484), 1481-1495.

Angelucci, M, Karlan, D., Zinman, J., 2015. Microcredit impacts: evidence from a randomized microcredit program placement by Compartamos Banco. Am. Econ. J. 7, 151-182.

Annan, J., Bundervoet, T., Seban, J., Costigan, J., 2013. Urwaruka Rushasha (New Generation): a randomized impact evaluation of village savings and loan associations and family-based interventions in Burundi. Eval. Brief.

Attanasio, O, Augsburg, B., De Haas, R., Fitzsimons, E., Harmgart, H., 2015. The impacts of microfinance: evidence from joint-liability lending in Mongolia. Am. Econ. J. 7, 90-122

Augsburg, B., De Haas, R., Harmgart, H., Meghir, C., 2015. The impacts of microcredit: evidence from Bosnia and Herzogovina. Am. Econ. J. 7, 183-203.

Avdeenko, A., Gilligan, M.J., 2015. International interventions to build social capital: lab-in-the-field evidence from Sudan. Am. Polit. Sci. Rev. 109 (3).

Banerjee, A., Chandrasekhar, A.G., Duflo, E., Jackson, M.O., 2018. Changes in Social Network Structure in Response to Exposure to Formal Credit Markets King Center on Global Development Working PaperAvailable at https://kingcenter.stanford.edu/publications/ changes-social-network-structure-response-exposure-formal-credit-markets .

Banerjee, A., Duflo, E., Glennerster, R., Kinnan, C., 2015. The miracle of microfinance? Evidence from a randomized evaluation. Am. Econ. J. 7, 22-53.

Barrett, S., 2005. Environment and Statecraft: the Strategy of Environmental Treaty-Making. Oxford University Press, New York.

Beaman, L., Karlan, D., Thuysbaert, B., 2014. Saving for a (Not So) Rainy Day: aA Randomized Evaluation of Savings Groups in Mali, p. 20600 NBER Working Paper.

Berg, J., Dickhaut, J., McCabe, K., 1995. Trust, reciprocity, and social history. Games Econ. Behav. 10 (1), 122-142.

Brody, C., de Hoop, T., Vojtkova, M., Warnock, R., Dunbar, M., Murthy, P., Dworkin, S.L., 2017. Can self-help groups improve women's empowerment? A systematic review. J. Dev. Effect. 9 (1), 15-40.

Button, K., Ioannidis, J., Mokrysz, C., et al., 2013. Power failure: why small sample size undermines the reliability of neuroscience. Nat. Rev. Neurosci. 14 $365-376$.

Cameron, A., Gelbach, J., Miller, D., 2008. Bootstrap-based improvements for inference with clustered errors. Rev. Econ. Stat. 90 (3), $414-427$.

Cardenas, J.C., Carpenter, J., 2008. Behavioral development economics: lessons from field labs in the developing world. J. Dev. Stud. 44, 337-364.

Carter, I. 2013. Releasing Potential: a facilitator's learning resource for self-help groups. https://www.tearfund.org/Sites/TILZ/Themes/Church/Self-help_ groups.

Casini, P., Vandewalle, L., 2017. Public good provision in indian rural areas: the returns to collective action by self -help groups. World Bank Econ. Rev. 31, 97-128.

Chen, M., 2007. Membership-Based Organizations of the Poor. Psychology Press.

Chuang, Y., Schechter, L., 2015. Stability of experimental and survey measures of risk, time and social preferences: a review and some new results. J. Dev. Econ. 117, 151-170.

Clingingsmith, D., Khwaja, A.I., Kremer, M., 2009. Estimating the impact of the Hajj: religion and tolerance in Islam's global gathering. Q. J. Econ. 124 (3), $1133-1170$.

Cohen, J., 1988. Statistical Power Analysis for the Behavioral Sciences. Routledge.

Colletta, N., Cullen, M., 2000. Violent Conflict and the Transformation of Social Capital: Lessons from Cambodia, Rwanda, Guatemala and Somalia. World Bank, Washington DC.

Crepon, B., Devoto, F., Duflo, E., Pariente, W., 2015. Estimating the impact of microcredit on those who take it up. Am. Econ. J. 7, 123-150

Datta, U., 2014. Socio-economic impacts of JEEVika: a large-scale self-help group project in Bihar, India. World Dev. 68, 1-18.

Deininger, K., Liu, Y., 2013a. Economic and social impacts of an innovative self-help group model in India. World Dev. 43, 149-163.

2013b. Evaluating program impacts on mature self-help groups in India. World Bank Econ. Rev. 27 (2), 272-296.

Desai, R., Joshi, S., 2013. Collective Action and Community Development Evidence from Self-Help Groups in Rural India World Bank Policy Research Working Paper. 6547.

Duvendack, M., Palmer-Jones, R., Copestake, J.G., Hooper, L., Loke, Y., Rao, N., 2011. What is the Evidence of the Impact of Microfinance on the Well-Being of Poor people?. EPPI-Centre, Social Science Research Unit, Institute of Education, University of London, London ISBN: 978-1-907345-19-7.

Engel, Christophe, 2011. Dictator games: a meta-study. Exp. Econ. 14, 583-610.

Entz, M., Karsgaard, J. and M. Saomons. 2016. An Overview of Savings and Self-help Groups, Their Contributions to Improved Food Security and How to Improve Their Function: a Review of the Literature. Available at https://www.prismaweb.org/nl/wp-content/uploads/2017/ 07/An-Overview-of-Savings-and-Self-Help-Groups-Their-Contributions-to-Improved-Food-Security-and-How-to-Improve-their-Function\%E2\%94\% 82Entz-Karsgaard-Salomons\%E2\%94\%82November-2016.pdf

Fafchamps, M., La Ferrara, E., 2012. Self-help groups and mutual assistance: evidence from Kenyan Slums. Econ. Dev. Cult. Change 60 (4), $707-734$.

Fehr, E., Schmidt, K.M., 1999. A theory of fairness, competition, and cooperation. Q. J. Econ. 114 (3), 817-868. 
Feigenbaum, B., Field, E., Pande, R., Rigol, N., Sarkar, S., 2014. Do group dynamics influence social capital gains among microfinance clients: evidence from a randomized experiment in urban India. J. Policy Anal. Manag. 44, 932-949.

Feigenbaum, B., Field, E., Pande, R., 2013. The economic returns to social interaction. Rev. Econ. Stud. 80 (4), $1459-1483$.

Fernadez, A.P., 2006. History and spread of the self-help affinity group movement in india: the role played by IFAD. Int. Fund Agric. Dev.. Available at https://www.microfinancegateway.org/library/history-and-spread-self-help-affinity-group-movement-india-role-played-ifad .

Gash, M., Odell, K., 2013. The Evidence-Based Story of Savings Groups: aA Synthesis of Seven Randomized Control Trials The SEEP NetworkAvailable at https://www.freedomfromhunger.org/sites/default/files/FINAL_Evidence-Based_Savings_Web.pdf .

Ghatak, M., Guinnane, T.W., 1999. The economics of lending with joint liability: theory and practice. J. Dev. Econ. 60, 195-228.

Graafland, J. and W. Rijneveld. 2016. The contribution of self-help groups in the horn of Africa to a range of outcomes: overview of the evidence of internal documents of TEAR and external literature. Available at https://www.prismaweb.org/ nl/wp-content/uploads/2017/07/The-contribution-of-Self-HelpGroups-in-the-Horn-of-Africa-to-a-range-of-outcomes\% percentE2\% percent94\% percent82Joanne-Graafland-and-Wouter-Rijneveld\% percentE2\% percent94\% percent82January-2016.pdf.

Greaney, BP, Kaboski, JP, Van Leemput, E, 2016. Can self-help group really be "self-help? Rev. Econ. Stud. 83, 1614-1644.

Henrich, J., Boyd, R., Bowles, S., Camerer, C., Fehr, E., Gintis, H., 2004. Foundations of Human Sociality: Economic Experiments and Ethnographic Evidence from Fifteen Small-Scale Societies. Oxford University Press, New York.

Henrich, J., et al., 2010. Markets, religion, community size, and the evolution of fairness and punishment. Science 327, 1480-1484.

Hoffman, E., McCabe, K., Smith, V., 1998. Behavioral foundations of reciprocity: experimental economics and evolutionary psychology. Econ. Inq. 36, $335-352$.

Johnson, N.D., Mislin, A.A., 2011. Trust games: a meta-analysis. J. Econ. Psychol. 32, 865-889.

Karlan, D., 2005. Using experimental economics to measure social capital and predict financial decisions. Am. Econ. Rev. 95 (5), $1688-1699$.

Karlan, D., Zinman, J., 2011. Microcredit in theory and practice: using randomized credit scores for impact evaluation. Science 332, $1278-1284$.

Karlan, D., Savonitto, B., Thusybaert, B., Udry, C., 2017. Impact of savings groups on the lives of the poor. Proc. Natl. Acad. Sci. 114, 3079-3084.

Kast, F., Meier, S., Pomeranz, D., 2012. Under-Savers Anonymous: EEvidence on Self-Help Groups and Peer Pressure as a Savings Commitment Device NBER Working Paper. 18417

Kingdom of Cambodia. 2008. General Population Census of the Kingdom of Cambodia, available at: https://www.nis.gov.kh/index.php/en/15-gpc/ 14-population-census-2008-final-result [Accessed 10 June 2020]

Khanna, M., Kochhar, N., Palaniswamy, N., 2015. A retrospective impact evaluation of the tamil nadu empowerment and poverty alleviation (Pudhu Vaazhu) project. J. Dev. Stud. 51, 1210-1223.

Kerbo, H.R., 2011. The Persistence of Cambodian Poverty: From the Killing Fields to Today. McFarland and Co, Jefferson NC.

Kim, J., 2009. Assessing the incremental effects of combining economic and health interventions: the IMAGE study in South Africa. Bull. World Health Organ. 87, 824-832.

Kling, JR, Liebman, JB, Katz, LF, Sanbonmatsu, L, 2004. Moving to Opportunity and Tranquility: NNeighborhood Effects on Adult Economic Self-Sufficiency and Health from a Randomized Housing Voucher Experiment KSG Working Paper. RWP04-035.

Ksoll, C., Bie Lilleor, H., Helth Lonborg, J., Dahl Rasmussen, O., 2016. Impact of village savings and loan associations: evidence from a cluster randomized trial. J. Dev. Econ. 120, 70-85.

LEAP, 2012. Pilot Phase - Brief Update of Report. Livelihood Enhancement \& Association of the Poor in Siem Reap (LEAP) PPA No. Q7100-KH.

Levitt, S.D., List, J.A., 2007. What do laboratory experiments measuring social preferences reveal about the real world. J. Econ. Perspect. 21, 153-174.

Mansuri, G., Rao, V., 2013. Localizing development: does participation work? Policy Research Report. The World Bank, Washington, DC.

MacKinnon, J.G., Webb, M.D., 2017a. Wild bootstrap inference for wildly different cluster sizes. J. Appl. Econ. 32 (2), $233-254$.

MacKinnon, J.G., Webb, M.D., 2017b. Pitfalls when estimating treatment effects using clustered data. Polit. Methodol. 24 (2), $20-31$.

MacKinnon, J.G., Webb, M.D., 2018. The wild bootstrap for few (Treated) clusters. Econ. J. 21 (2), 114-135.

Ministry of Planning. 2013a. Identification of Poor Households (IDPoor). Available at http://www.mop.gov.kh/Projects/IDPoor/tabid/154/Default.aspx

Ministry of Planning. 2013b. Cambodia’s Identification of Poor Households Program (IDPoor). Available at http://www.medicam-cambodia.org/activities/info/ 4ms/source/2009/7/handouts/Presentation3.pdf

Pitt, M.M., Khandker, S.R., Cartwright, J., 2006. Empowering women with microfinance: evidence from Bangladesh. Econ. Dev. Cult. Change 54, 791-831.

Pronyk, P.M., 2006. Effect of a structural intervention for the prevention of intimate-partner violence and HIV in rural South Africa: a cluster-randomized trial. Lancet N. Am. Ed. 368, 1973-1983.

Putnam, R., 2000. Bowling Alone: the Collapse and Revival of American Community. Simon and Schuster.

Roodman, D., MacKinnon, J., Nielsen, M., Webb, M., 2019. Fast and wild: bootstrap inference in Stata using boottest. Stata J. 19 (1), 4-60.

Schechter, L., 2007. Traditional trust measurement and the risk compound: an experiment in rural Paraguay. J. Econ. Behav. Organ. 62 (2), $272-292$.

Swain, R.B., Varghese, A., 2009. Does Self-help group participation lead to asset accumulation. World Dev. 37 (10), $1674-1682$.

Tarozzi, A., Desai, J., Johnson, K., 2015. The impacts of microcredit: evidence from Ethiopia. Am. Econ. J. 7, 54-89.

Van Rooyen, C., Stewart, R., De Wet, T., 2012. The impact of microfinance in Sub-Saharan Africa: a systematic review of the evidence. World Dev. 40, 2249-2262.

Weingart, A., Kirk, M., 2012. Escaping poverty traps? Action and property rights in postwar rural Cambodia. In: Mwangi, E., Markelova and, H., Meinzen-Dick, R. (Eds.), Collective Action and Property Rights For Poverty Reduction: Insights from Africa and Asia eds. University of Pennsylvania Press.

Zellmer, Jennifer, 2003. Linear public goods experiments: a meta-analysis. Exp. Econ. 6, 299-310. 